\title{
Ignition dynamics of DME/methane-air reactive mixing layer under reactivity controlled compression ignition conditions: Effects of cool flames
}

Tai Jin ${ }^{1,2}$, Yunchao $\mathrm{Wu}^{3}$, Xujiang Wang ${ }^{1}$, Kai H. Luo ${ }^{1 *}$, Tianfeng $\mathrm{Lu}^{3}$, Kun

Luo $^{2}$, Jianren Fan ${ }^{2}$

1. Department of Mechanical Engineering, University College London, London WC1E 7JE, United Kingdom

2. State Key Laboratory of Clean Energy Utilization, Zhejiang University, Hangzhou 310027, P. R. China

3. Department of Mechanical Engineering, University of Connecticut, Storrs CT 06269, USA

*Corresponding author E-mail: k.luo@ucl.ac.uk

Accepted by

Applied Energy 


\section{Abstract}

A study of ignition dynamics in a turbulent dimethyl ether (DME)/methane-air mixture under Reactivity Controlled Compression Ignition (RCCI) conditions was conducted using direct numerical simulation. Initially, the directly-injected DME and in-cylinder premixed methaneair mixture are partially mixed to form a mixing layer in between. A reduced $\mathrm{DME} / \mathrm{CH}_{4}$ oxidization mechanism, consisting of 25 species and 147 reaction steps, is developed and validated. Ignition is found to occur as a two-stage process. Low-temperature autoignition is first initiated in the fuel-rich part of the mixture and then transits to a cool flame, propagating towards the even richer mixture through a balanced reaction-diffusion mechanism. Cool flames not only develop in the mixing layer, but also in the initially stratified DME/methane-air mixture. The formation of high-temperature autoignition kernels is earlier than that in the homogeneous mixture at the same mixture fraction, which is thought to be accelerated by the cool flame. The expanding flames from high-temperature kernels are connected with the neighboring flames before they engulf the stoichiometric mixture iso-lines. The four branches of typical tetrabranchial flames, i.e. cool flame, fuel-rich premixed flame, diffusion flame, fuellean premixed flame coexist in the field. The fuel-lean premixed flame branch finally triggers the premixed methane-air flame. The multi-stage and multi-mode nature of the ignition process highlights the intractable challenge to model the RCCI engine combustion.

Keywords: Ignition, cool flame, DME, tetrabranchial flame, RCCI, DNS 


\section{Introduction}

With the increasing concern about diesel engine emissions, including nitrogen oxides $\left(\mathrm{NO}_{\mathrm{x}}\right)$ and particulate matter $(\mathrm{PM})$, and the rising crisis of energy insecurity, utilization of alternative and sustainable fuels in diesel engines is regarded as a promising solution [1-3]. Natural gas (NG) is a highly attractive fuel because of its low emissions, low-carbon qualities as a transportation fuel $[4,5]$. Although compressed natural gas can be used in diesel engines, it causes poor performance and emissions characteristics at certain engine operating loads. The poor ignitability of natural gas could also result in increased emissions of unburnt hydrocarbons (HC) and carbon monoxide (CO) $[6,7]$. The use of natural gas fuels in compression ignition (CI) engines through dual fuel technology represents a promising way to reach a good solution. Dual-fuelling in CI engines is a mode of combustion where a small pilot injection of highcetane fuel (e.g. diesel) ignites a premixed high-octane fuel (e.g. methane) and air mixture. This allows conventional CI engines to lower their emissions of smoke and nitrogen oxides (NOx) while maintaining their characteristically high thermal efficiencies [8, 9].

There are different approaches to the dual fuel (DF) engine control strategy $[4,10]$. Reactivity-Controlled Compression Ignition (RCCI) called by Kokjohn et al. [11], is a dual fuel engine combustion technology that uses in-cylinder blending of two fuels with different autoignition characteristics to control combustion phasing and heat release rate. RCCI is a promising low-temperature combustion (LTC) technique with significant potential for improving thermal efficiency while reducing NOx and PM emissions compared to the conventional IC engines [12]. Experiments and computational studies on RCCI using a variety of fuel combinations can be referred to the reviews by Reitz et al. [13], Paykani et al. [14] and Li et al. [15]. The reactivity difference between high and low reactive fuels in RCCI application plays an important role in controlling the combustion phasing and shaping the heat release curve $[16,17]$. Benajes et al. $[18,19]$ tested the effects of the direct injection timing and 
blending ratio on the performance and engine-out emissions in a heavy duty RCCI engine with alternative low reactivity fuels, including E10-95, E20-95, E10-98 and E85. Dempsey et al. $[20,21]$ investigated the effects of fuel additive on single fuel RCCI engine, with fuels like gasoline, ethanol, methanol, and blends of alcohol and gasoline. Ansari et al. [22] recently conducted an experimental investigation into the effects of high reactive fuel on combustion and emission characteristics of the NG/diesel RCCI engine. It has been found that local reactivity plays a fundamental role to enhance the RCCI combustion propagation, which proceeds gradually from high-reactivity to low-reactivity regions, reducing the incomplete combustion [19, 23] [22].

Understanding the mixing and auto-ignition process of RCCI combustion is very important in order to obtain the required fuel reactivity distribution in the cylinder. Kokjohn et al. [24] adopted high-speed chemiluminescence imaging in an optically accessible engine to visualize the iso-octane/n-heptane RCCI combustion process. They also used fuel tracer fluorescence imaging to relate the fuel distribution prior to ignition to the ignition locations and the preferred direction of reaction zone growth. Kokjohn et al. [25] further analyzed the role of equivalence ratio, temperature, and fuel reactivity stratification for heat-release rate control. Tang et al.[26] used multiple laser diagnostic techniques to investigate the effects of fuel stratification degree on ignition in a light-duty RCCI optical engine. Srna et al. [27] recently optically measured the effects of methane on pilot-fuel auto-ignition in dual-fuel engine. Although the optical engine experiments provide a qualitative description of the RCCI combustion event, the mechanism controlling the local growth of the autoignited zones is unclear, which has been further explored through numerical modeling. Various numerical methods, based on Reynolds-averaged Navier-Stokes (RANS) simulation and Large Eddy Simulation (LES), have been adopted for engine combustion modeling. Neiman et al. [28] used the multidimensional computational fluid dynamics (CFD) code, KIVA3V, coupled with the 
CHEMKIN chemistry tool to optimize NG/diesel RCCI engine parameters including fuel fraction, DI fuel quantity split, injection pressure of diesel and amount of EGR. Poorghasemi et al. [29] investigated the effects of diesel injection strategies on NG/diesel RCCI combustion characteristics in a light duty diesel engine using Converge model. Li et al. [30] numerically investigated the double injection techniques in a gasoline and biodiesel fuelled RCCI engine. A transition from reactivity-controlled to reactivity \& mixing controlled combustion mode has been observed under various operating conditions. Benajes et al. [31] reported an experimental and numerical study to understand mixing and autoignition processes in gasoline/diesel RCCI combustion. Zhou et al. [32] proposed a Lagrangian marker particle based flame propagation model to predict the combustion and flame propagation in the RCCI partially premixed combustion. The broad spectrum of combustion regimes in RCCI engines, where lowtemperature combustion, auto-ignition and partially premixed combustion are mainly involved, makes the combustion modeling in these engines very challenging. The fundamental understanding of RCCI combustion is still limited by the capability of RANS/LES-based simulations [33], which rely heavily on empirical turbulence modeling and combustion modeling. Furthermore, the ignition dynamics, flame propagation characteristics, turbulent flame speeds, and emissions generation characteristics of natural gas in RCCI engine conditions are still not well known.

Direct numerical simulation (DNS) resolves all relevant flow and chemical species time scales and length scales, and is currently a valuable scientific tool for understanding the effects of turbulent mixing on autoignition kernels, especially in the presence of thermal and composition stratification [33-35]. In previous studies, the ignition characteristics of RCCI combustion under constant volume condition have been investigated via DNS. Bhagatwala et al. [34] reported one- and two-dimensional DNSs of ignition of primary reference fuel (PRF) mixture (iso-octane/n-heptane) under RCCI conditions. Deflagration and spontaneous ignition 
fronts were found to coexist and their proportions during the ignition process were also investigated. The overall ignition patterns of a lean PRF/air mixture under RCCI conditions were presented by Luong et al. [33, 35], and compared with that under stratified charge compression ignition (SCCI) conditions. It was found that the portion of deflagration mode of combustion became larger with increasing fuel stratification. In the above studies, the DNSs were conducted with the assumptions that all the in-cylinder injections were completed and injected fuel/air mixtures were well mixed prior to the top dead center (TDC). However, the ignition dynamics during injection or right after injection, while the directly-injected fuel and in-cylinder fuel/air mixture form a mixing layer in between, are not well understood. This mixing layer affects the whole ignition and flame development process.

A two-stage autoignition under diesel engine-relevant conditions has been observed [36], involving pre-ignition reactions due to low-temperature combustion (LTC), followed by the main ignition due to high-temperature combustion (HTC). Krisman et al. [37, 38] recently investigated the two-stage ignition in a turbulent mixing layer of dimethyl ether (DME)-air mixture by DNS. It was found that LTC significantly affected the timings and locations of the second stage autoignition. Krisman et al. [39] also studied the two-stage autoignition and edge flames in a three-dimensional temporally evolving planar jet of n-heptane in a stationary layer of air with a global chemical model. Borghesi et al. [40] presented a DNS of a temporal jet between n-dodecane and diluted air undergoing spontaneous ignition at conditions relevant to low-temperature diesel combustion. It was found that low-temperature heat release in slightly rich fuel regions initiates multiple cool flame kernels that propagate towards very rich fuel regions through a reaction-diffusion mechanism, which accelerates the high-temperature ignition. In our previous work, the ignition of homogeneous premixed methane-air mixture by piloted DME under diesel engine-relevant conditions has been studied [41]. It has been found the first-stage LTC transits to cool flame, high-temperature ignition kernels develop to 
propagating triple flames along the stoichiometric mixture, which initiate the premixed methane-air flame. Recently, Yu et al. [42] investigate the ignition characteristics of a lean PRF/air mixture with a mixing layer under RCCI conditions. Preliminary results qualitatively show that the mixing layer affects the development of low-temperature combustion and subsequently the high-temperature combustion. However, the effects of mixing layer on, such as the timing and locations of high-temperature ignition, scalar dissipation, high-temperature flame development et al., are not fully discussed, which needs further exploration.

The goal of this study is to extend the prior simulation studies to ignition characteristics of DME/methane-air mixture with mixing layer under RCCI conditions, and to quantify the relative roles of spontaneous low-temperature autoignition and cool flame propagation, as well as its effects on high-temperature ignition. Methane acts as the low-reactivity fuel and DME is chosen as the high-reactivity fuel, regarding its excellent auto-ignition properties[43] [4447].This paper is organized as follows: In Section 2, the computational configuration and initial conditions are first described, followed by a brief introduction of the numerical methods. Validations of the reduced chemical mechanism for $\mathrm{DME} / \mathrm{CH}_{4}$ oxidization and the homogeneous ignition delay calculations are then presented. In Section 3, the transient and statistical results are first discussed. Low-temperature combustion and high-temperature ignition are then investigated in detail. Finally, concluding remarks are given in Section 4.

\section{Numerical implementation}

\subsection{Configuration}

In dual fuel RCCI engines, the low reactivity fuel (i.e. $\left.\mathrm{CH}_{4}\right)$ is typically premixed and the high reactivity fuel (i.e. DME) is direct-injected. Thus, the equivalence ratio of $\mathrm{CH}_{4}$ is nearly uniform throughout the combustion chamber. The direct-injected DME would then impose a distribution of equivalence ratio, temperature onto the uniform $\mathrm{CH}_{4}$ distribution. In the present study, we focus on the condition right after the directly-injection of DME, while the directlyinjected fuel and in-cylinder fuel/air mixture form a mixing layer in between. A square two- 
dimensional domain of $3.2 \mathrm{~mm}(L)$ is considered as the computational domain. This is to mimic the combustion chamber of a diesel engine at the top dead center (TDC). Periodic boundary conditions are applied in both the horizontal $(x)$ and vertical $(y)$ directions, effectively resulting in a constant volume system. Figure 1 shows a schematic of the configuration.

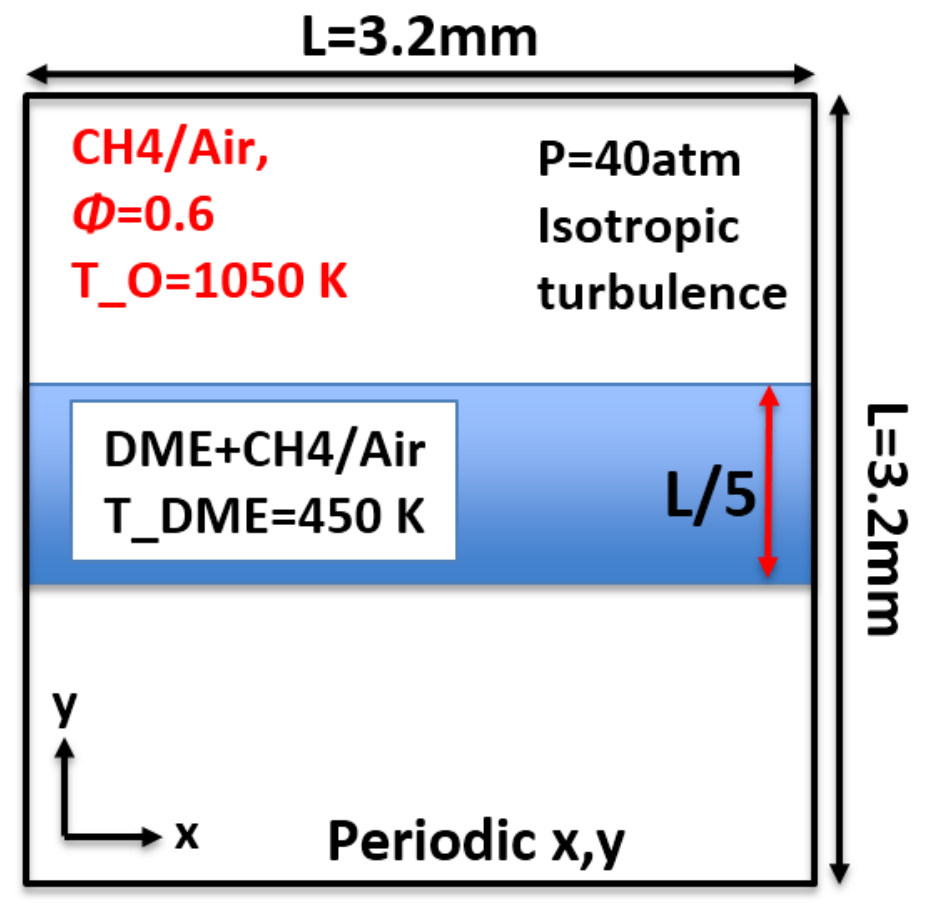

Fig. 1 Sketch of the computational domain

At the onset of the simulation, a premixed mixture of methane and air with an equivalence ratio of 0.6 is homogeneously distributed in the whole domain. A horizontal strip of fuel is imposed to the methane/air mixture in the center of the domain, to generate the mixing layer with a gradient of mixture fraction. The mixture fraction $\xi$ is defined based on the mass fraction of $\mathrm{N}_{2}, \xi=\left(Y_{N 2}-Y_{N 2}^{o x}\right) /\left(Y_{N 2}^{f}-Y_{N 2}^{o x}\right)$. It ranges from 0 in the premixed methane/air mixture to 1 in the pure DME fuel. To mimic the partial mixing of DME and methane/air mixture after injection, the mean mixture fraction $\bar{\xi}$ imposed in the central region is 0.4 , with a fluctuation $\xi^{\prime}$ of 0.025 . The width of the central mixing region is set to be $L / 5$. The initial profile of mixture fraction across the mixing layer on each side of the fuel strip is given by a specified hyperbolic tangent mixture fraction profile, $\xi(y)=\left(1+\tanh \left(\frac{a b s\left(y-\frac{1}{10} L y\right)}{\delta}\right)\right) / 2 . \delta$ is the initial thickness 
of the mixing layer, $\delta=24 \mu \mathrm{m}$. The gas composition is then specified according to the mixture fraction profile. The temperature of the premixed methane/air mixture is $1050 \mathrm{~K}$, and the injected DME is $450 \mathrm{~K}$. The temperature of the mixture of DME/methane/air in the mixing layer is determined by adiabatic mixing between DME and the pre-imposed methane/air mixture. Figure 2 shows the initial temperature, mixture fraction, mass fraction of DME and $\mathrm{CH}_{4}$.
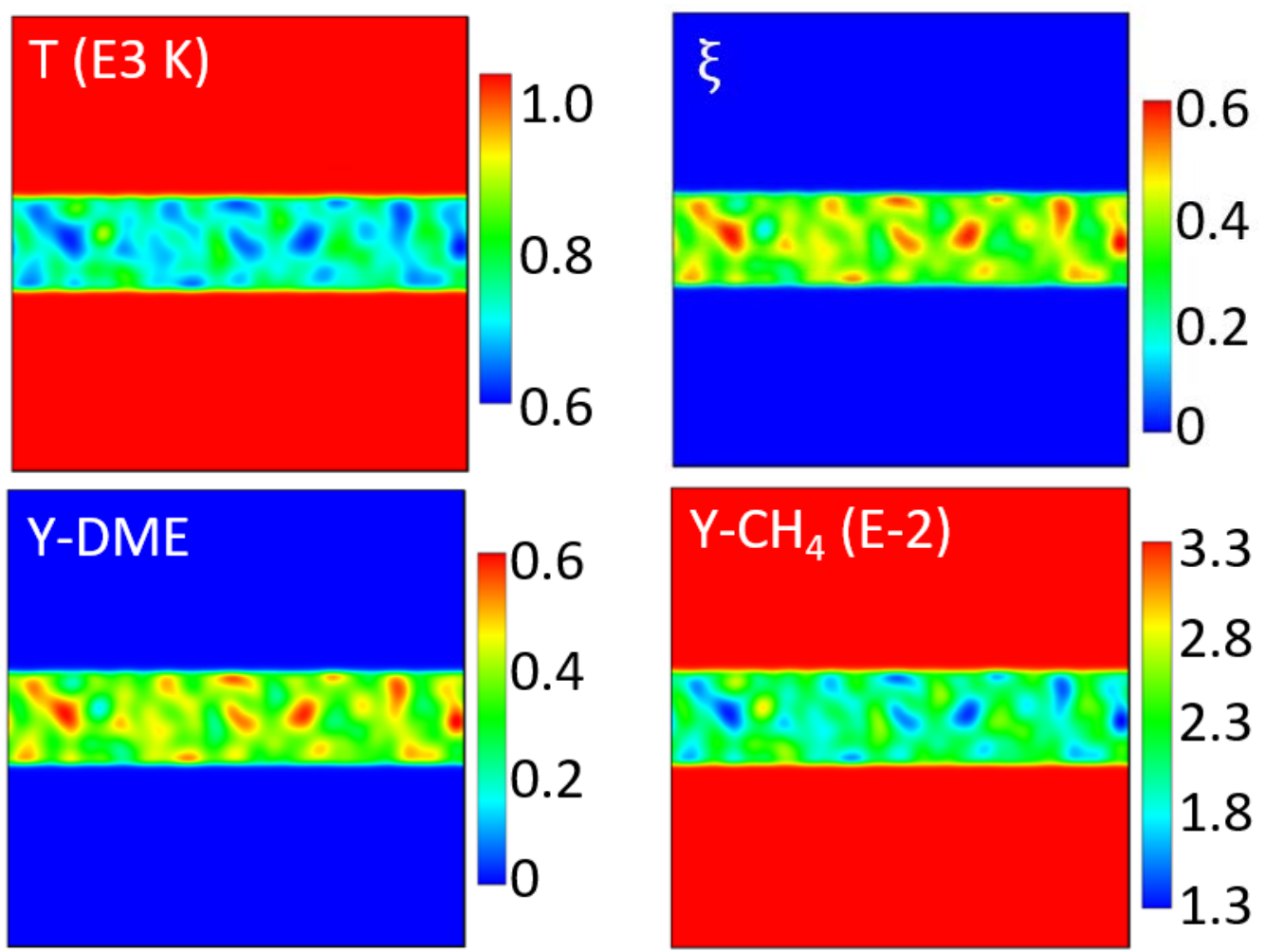

Fig.2 Initial conditions of temperature, mixture fraction, mass fraction of DME and $\mathrm{CH}_{4}$

The mean initial velocity field was set to zero, and the initial random two-dimensional velocity field was generated by the Passot-Pouquet spectrum, $E(k)=$ $\frac{32}{3} \sqrt{\frac{2}{\pi}} \frac{u^{\prime 2}}{k_{e}}\left(\frac{k}{k_{e}}\right)^{4} \exp \left[-2\left(\frac{k}{k_{e}}\right)^{2}\right]$, where $k$ is the wave number, the subscript $\mathrm{e}$ is for the most energetic wave number, and $u^{\prime}$ is the root mean square (RMS) velocity. The turbulence parameters were set such that $u^{\prime}=0.5 \mathrm{~m} / \mathrm{s}$ (turbulence intensity) and $l_{\mathrm{t}}=0.1 \mathrm{~mm}$ (integral eddy scale). The turbulent Reynolds number $\left(\operatorname{Re}=u^{\prime} l_{\mathrm{t}} / v\right)$ based on the integral length scale is 
15.2, where the kinematic viscosity of the $\mathrm{CH}_{4}$-air mixture at the initial conditions is used $(v=$ 3.30e-6 m²/s at 40 atm and $1050 \mathrm{~K}$ ). The corresponding Damkhöler number ( $D a$, defined as $\left.D \mathrm{a}=\tau_{\text {turb }} / \tau_{\left(\xi=\xi_{m r}\right)}\right)$ is about 0.866. $\tau_{\text {turb }}$ is the large eddy time defined as $\tau_{\text {turb }}=l_{t} / u^{\prime} . \tau_{\left(\xi=\xi_{m r}\right)}$ is the second-stage ignition delay time of the most reactive mixture fraction measured in the homogeneous reactor. Considering the prohibitive cost of three-dimensional (3D) simulation, two-dimensional (2D) DNS is conducted here. In general, 3D turbulence is different from 2D turbulence because of the vortex-stretching effects associated with a mean velocity gradient. However, in decaying homogeneous isotropic turbulence, there is no mean velocity gradient and thus no vortex stretching, so that 2D and 3D simulations are essentially the same $[48,49]$. It should be noted that 2D decaying homogeneous isotropic turbulence is widely used for fundamental research of turbulence and turbulent combustion. Such a 2D configuration is also adopted in the present study, where the RMS velocity $u^{\prime}=0.5 \mathrm{~m} / \mathrm{s}$ and the integral turbulent Reynolds number is 15.2 .

\subsection{Numerical methods}

The full compressible Navier-Stokes equations, species and energy conservation equations for a reacting gas mixture are solved with an in-house DNS code. A fourth-order explicit Runge-Kutta method for time integration and an eighth-order central differencing scheme for spatial discretization are used with a tenth-order filter for removing spurious highfrequency fluctuations in the solution. CHEMKIN software libraries [50] are linked to the current code to evaluate reaction rates, as well as thermodynamic and transport properties for both the individual species and the averaged mixture. A detailed description of the DNS code is given in our previous publications $[51,52]$. The DNS solver has been adopted to simulate the two-stage autoignition of dimethyl ether (DME)/air mixture under diesel engine relevant conditions and investigate the generated tetrabrachial flames [53]. 


\subsection{Combustion chemistry}

The chemical mechanism used for this parametric study has been reduced from a validated detailed DME/CH 4 mechanism (Mech_56.54) [54]. The detailed mechanism has been extensively validated using available literature data including flow reactor, jet-stirred reactor, shock-tube ignition delay times, shock-tube speciation, flame speed and flame speciation data for DME/ $\mathrm{CH}_{4}$ blends, pure DME and pure $\mathrm{CH}_{4}$ [54], respectively. The direct relation graph aided sensitivity analysis (DRGASA) [55] is used to remove species to create a 34 species skeletal mechanism. Linearized quasi-steady state approximation (LQSSA) [56] is further applied to reduce the number of transported species and 9 QSS species are identified using a criterion based on computational singular perturbation (CSP) [57], resulting a final 25 species reduced mechanism. Lastly, to ensure the application of the explicit time integration in the DNS, the method of dynamic stiffness removal [58] is employed to eliminate chemical timescales shorter than 10 ns. This mechanism was validated extensively against the detailed mechanism for ignition delay time, perfectly stirred reactor (PSR) extinction residence time, laminar premixed flame speed, and species profiles in premixed laminar flames and opposed jet diffusion flames. Selected validations of the reduced mechanism for ignition delay times, extinction residence time and extinction temperature, and laminar flame speed at conditions relevant to the current study can be found in Figs. 3, 4 and 5. In figures 3, 4 and 5, $\alpha$ and $\Phi$ represent the DME mole percentage in the $\mathrm{CH}_{4} / \mathrm{DME}$ mixtures and equivalence ratio respectively. The reduced mechanism shows no observable deviation from the detailed mechanism in both extinction time and ignition delay times, while quite small but acceptable deviations exist for the laminar flame speed. 


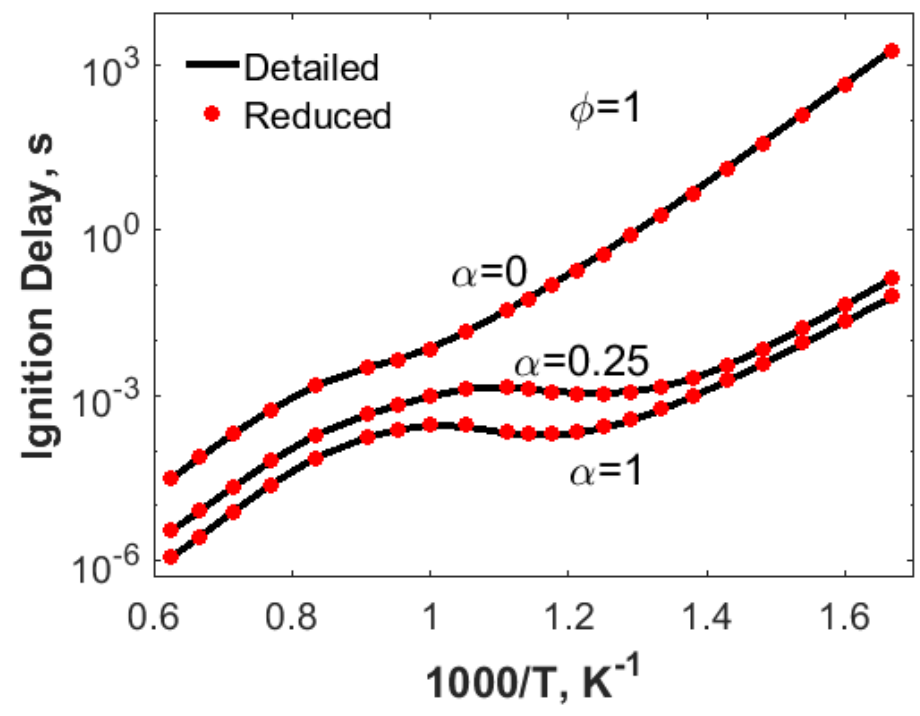

Fig. 3. Ignition delay times for stoichiometric DME/CH4/air mixtures with different DME mole percentages at $40 \mathrm{~atm}$ based on the detailed (black line) and reduced mechanisms (red symbols).

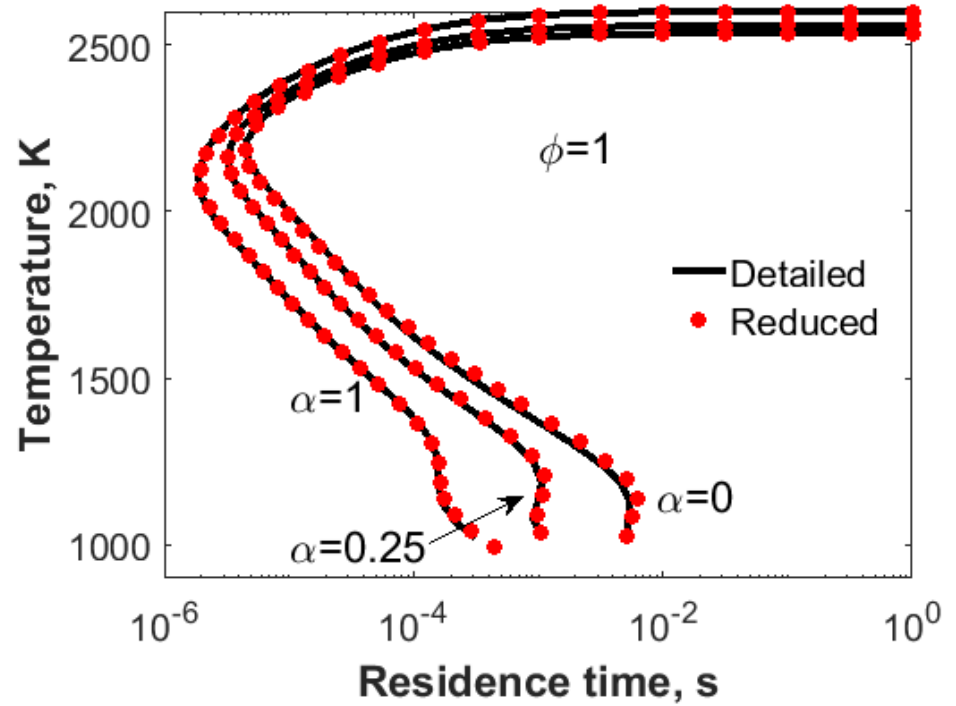

Fig. 4. Extinction residence times and extinction temperatures of PSR for stoichiometric $\mathrm{DME} / \mathrm{CH}_{4} /$ air mixtures with different DME mole percentages at $40 \mathrm{~atm}$ based on the detailed (black line) and reduced mechanism (red symbols). 


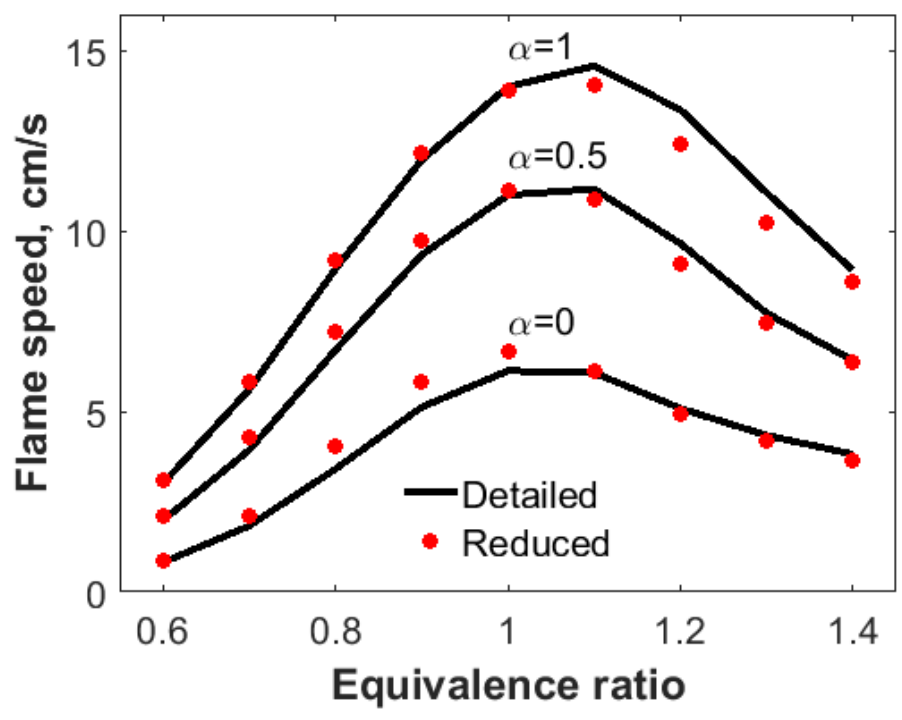

Fig. 5. Laminar flame speeds for $\mathrm{DME} / \mathrm{CH}_{4} /$ air mixtures as a function of equivalence ratio at $40 \mathrm{~atm}$ and a free stream temperature of $300 \mathrm{~K}$ based on the detailed (black line) and reduced mechanism (red symbols).

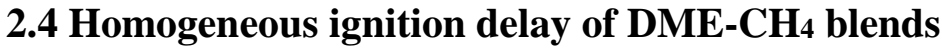

The homogeneous delay time calculations can help to understand the initial thermochemical condition. For hydrocarbon-based fuels, two-stage ignition processes are generally observed, in which the first stage ignition is governed by the low-temperature chemistry and the second stage ignition by high-temperature chemistry. For cases that undergo two-stage ignition, the first stage ignition delay time, $\tau 1$, is defined as the timing of the first peak in temperature rise rate, and the second stage ignition delay time, $\tau$, as the timing of the second peak in temperature rise rate. For cases undergo single stage ignition there is only the main ignition delay time, $\tau$. The methane/air mixture undergoes single stage ignition, while DME/air mixture generally undergoes two-stage ignition. It has been found that the addition of DME to methane enhances the reactivity of methane by increasing radical production at low temperature through DME's chain branching pathway, and through its unimolecular decomposition and relatively fast $\mathrm{H}$-atom abstraction rate constants at high temperature [54]. Thus the ignition delay times decrease with the increased DME concentration. Figure 6(a) shows the combined scatter of the ignition delay with respect to the mixture fraction. The 
ignition delay time is calculated with a constant pressure zero-dimensional homogeneous reactor in the Chemkin software [50]. With the addition of DME, the high-temperature ignition delay decreases significantly. A low-temperature ignition with relatively high heat release rate has been found and recognized as the first stage ignition. The first stage ignition can be clearly detected while $\xi>0.066$. The ignition delay times for the first- and second- stage ignition are not varied monotonically. A most reactive mixture fraction, when the ignition delay time is peak short, can be recognized for the first-stage ignition $\left(\xi_{\mathrm{mr}, 1}=0.141\right)$ and the second-stage ignition $\left(\xi_{\mathrm{mr}, 2}=0.195\right)$, respectively. Both of them are located in fuel-rich mixture, considering the stoichiometric mixture fraction $\xi_{\mathrm{st}}=0.041$. Figures $6(\mathrm{~b}) \&$ (c) show the spatial distribution of the low- and high-temperature ignition delay under the initial condition. The points with shortest ignition delay are located in the mixing layer, as well as some region in the central stratified mixture. One of the objectives of the present study is to reveal the low-temperature combustion effects on the high-temperature ignition.

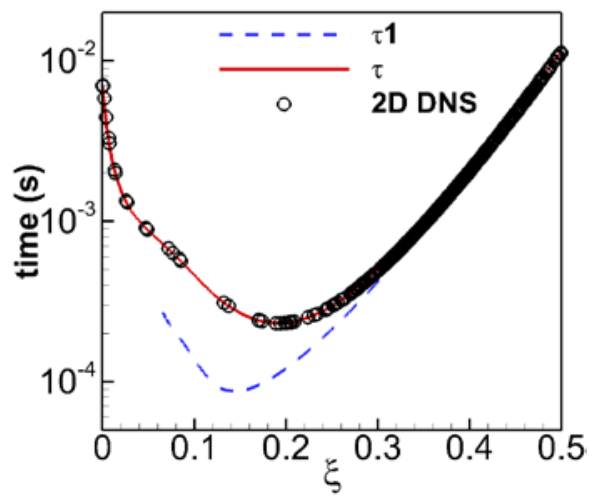

(a)

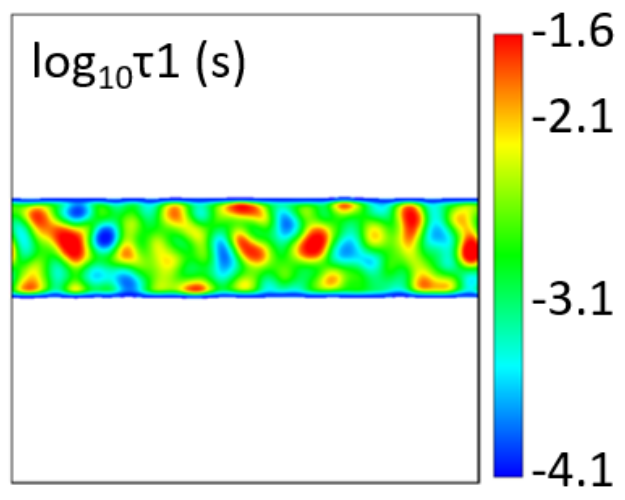

(b)

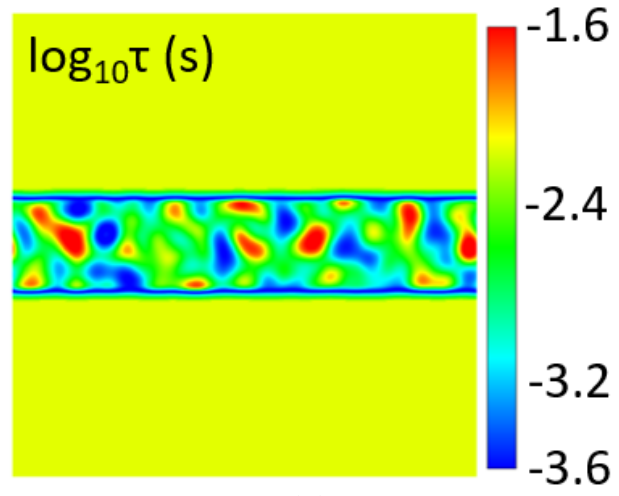

(c) 
Fig. 6 (a) Homogeneous ignition delay time in the mixture fraction space and the scatter distribution of the DNS case, spatially distribution of (b) the first-stage ignition delay time and (c) the second-stage ignition delay time at the initial condition.

\subsection{Numerical convergence}

Numerical convergence has been tested for 1D simulations under the same initial thermochemical conditions with the 2D simulation. The mean mixture fraction at the center is set to 0.4 . Periodic boundary conditions are used at both sides. The solution is advanced with a time step of $1 \mathrm{~ns}$. Grid sizes with $2 \mu \mathrm{m}, 1 \mu \mathrm{m}$ and $0.5 \mu \mathrm{m}$ were tested. The profiles of temperature at $\mathrm{t}=0.4 \mathrm{~ms}$ are compared in Fig. 7 . It is found that converged results can be obtained with three different grid sizes at $\mathrm{t}=0.1 \mathrm{~ms}$, where the low-temperature ignition occurs . However, after high-temperature ignition at $\mathrm{t}=0.4 \mathrm{~ms}$, converged results can only be obtained with the grid sizes of $1 \mu \mathrm{m}$ and $0.5 \mu \mathrm{m}$, while a faster propagation of the $\mathrm{CH} 4$-air flame is obtained with the grid size of $2 \mu \mathrm{m}$. The time step of $1 \mathrm{~ns}$ is chosen to capture the large heat release rate at high-temperature ignition, otherwise the simulation will diverge. Thus, for the 2D simulation, a uniform mesh with a grid spacing of $1 \mu \mathrm{m}$ was used in both $x$ and $y$ directions. The solution is advanced with a time step of $1 \mathrm{~ns}$.
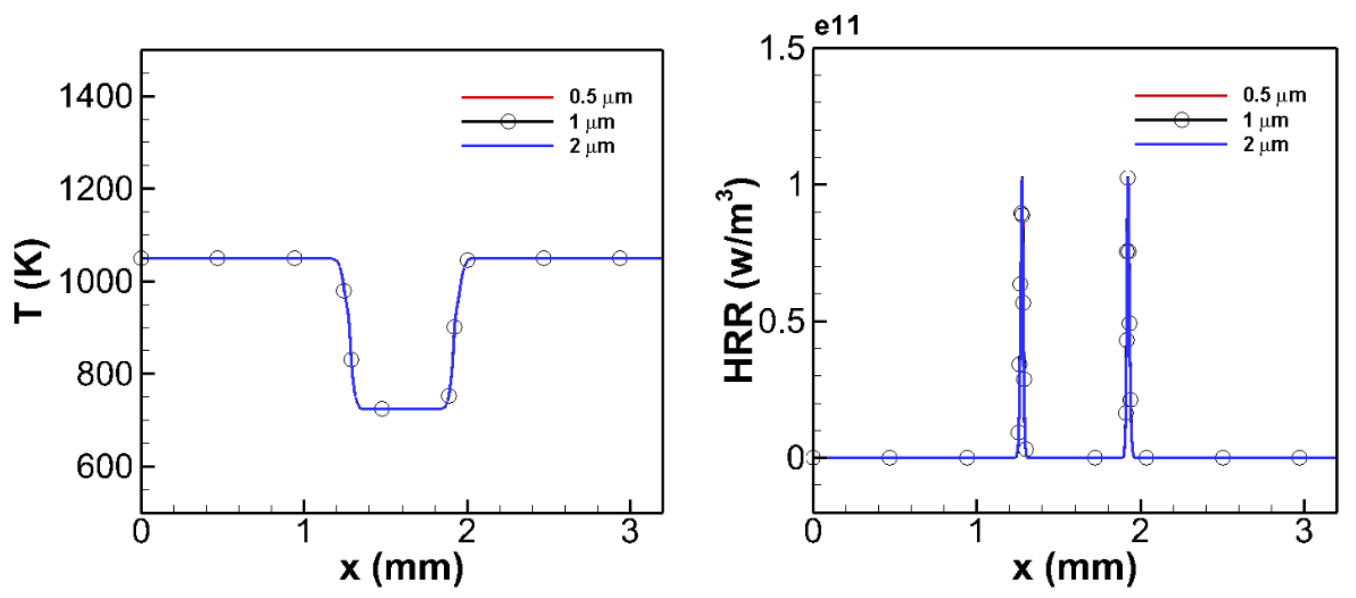

(a) 

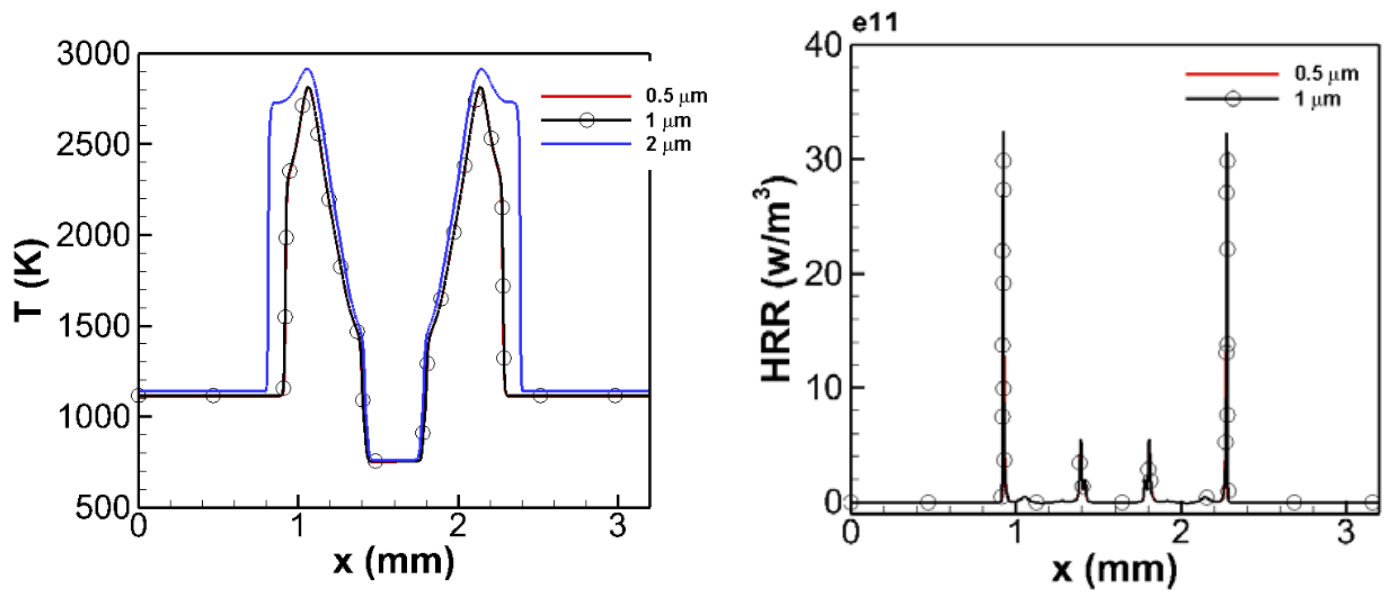

(b)

Fig. 7 Profiles of temperature (T) and heat release rate (HRR) with different grid sizes,(a) at t $=0.1 \mathrm{~ms}$; (b) at $\mathrm{t}=0.1 \mathrm{~ms}$.

\section{Results and discussion}

\subsection{Transient ignition process}

The overall ignition and flame development process can be qualitatively described by the sequential instantaneous images of temperature (T), heat release rate (HRR), as well as mass fractions of some typical species, such as methoxymethyl peroxy radical $\mathrm{CH}_{3} \mathrm{OCH}_{2} \mathrm{O}_{2}$ (a marker of LTC reactions), hydroxyl radical OH (marker of HTC reactions). To clearly illustrate the details of the contours, $1 / 4$ part $(1.6 \mathrm{~mm} \times 1.6 \mathrm{~mm}$, left middle part) of the domain is chosen and zoomed in Fig. 8, which is representative of the whole domain. The overall transient evolution of the flame initiation is generally consistent with previous results for the two-stage ignition in mixing layers $[38,53]$. Low-temperature ignition is first initiated in fuel rich mixture as shown in Fig. 8 at $t=0.08$ ms. The heat release rate caused by first stage ignition is spatially varied, as it is influenced by local scalar dissipation $\chi$, while higher value of $\chi$ would induce lower HRR. The LTC then moves up the mixture fraction gradient and finally develops to be a diffusion supported cool flame as demonstrated in Fig. $8(\mathrm{t}=0.16 \mathrm{~ms})$. The HRR, as well as the mass fraction of $\mathrm{CH}_{3} \mathrm{OCH}_{2} \mathrm{O}_{2}$, increases to a relatively high level in the cool flame, compared with the first-stage ignition. 
The transition from low-temperature ignition to cool flame in mixing layer has been discussed in previous studies $[39,53]$. However, this has not been reported in the previous RCCI simulations [33-35], where most of them are focused on the global ignition process at the stage when the dual fuel/air has been well mixed. Therein, the extent of premixed flame propagation versus ignition fronts is also quantified. It has been found that low-temperature heat release occurs via both flame propagation and through ignition fronts [34]. Nevertheless, the structure of the low-temperature propagating flame has not yet been described. During and right after the injection of the high-reactivity fuel (DME), mixing layer could exist between DME and the homogeneous premixed methane/air mixture, which is the condition investigated here. A propagating cool flame has been explicitly demonstrated in Fig. 8. Cool flames not only develop in the mixing layer, but also in the initially stratified DME/methane-air mixture in the central region. The role of cool flame during the ignition process will be analyzed statistically in the following Section 3.3. Species $\mathrm{CH}_{3} \mathrm{OCH}_{2} \mathrm{O}_{2}$ is an intermediate species purely associated with LTC and consumed at high temperatures. The transport budget for the LTC marker $\mathrm{Y}-\mathrm{CH}_{3} \mathrm{OCH}_{2} \mathrm{O}_{2}$ along the marked lines A-F will be analyzed to quantify the role of diffusion in supporting the LTC.

At $\mathrm{t}=0.24 \mathrm{~ms}$, it shows in Fig.8 that high-temperature ignition is discretely initiated in fuel rich mixture. The high-temperature kernels rapidly expand to leaner and richer mixtures, and gradually emerge with neighboring kernels at $\mathrm{t}=0.3 \mathrm{~ms}$ as shown in Fig. 8. The branch moves to richer mixture and then catches up the cool flame. The other branch expands to learner mixture, crosses the stoichiometric isoline and finally triggers the premixed methane/air flame. Due to the lower gradient of mixture fraction across the mixing layer and thus low scalar dissipation rate, the typical triple flame and its propagation along the $\xi_{\text {st }}$ iso-line found in our previous study, are not significant. The high-temperature flames connect with each other in fuel rich mixture before it engulfs the $\xi_{\text {st }}$ iso-line. However, the four branches, cool flame, 
fuel-rich premixed flame, diffusion flame, fuel lean premixed flame are still coexisting in the field, at $\mathrm{t}=0.34 \mathrm{~ms}$ as shown in Fig. 8. Temperature peaks around the stoichiometric mixture isoline. The distribution of species $\mathrm{OH}$ is consistent with high-temperature combustion, thus it can be regarded as the marker of HTC.

In the constant volume system analyzed in the present study, pressure of the system would increase due to gas expansion as a result of heat release from reactions. The low-temperature ignition induces a slight increase in pressure. The pressure of the computational domain increases slightly from the initial 40 atm to 41.25 atm at the beginning of the second stage ignition (0.24 ms). After that, temperature increases significantly due to the large heat release from high-temperature combustion, and pressure increases up to 67.03 atm till the end of the simulation when the premixed methane flame is completely initiated (0.4 ms). 


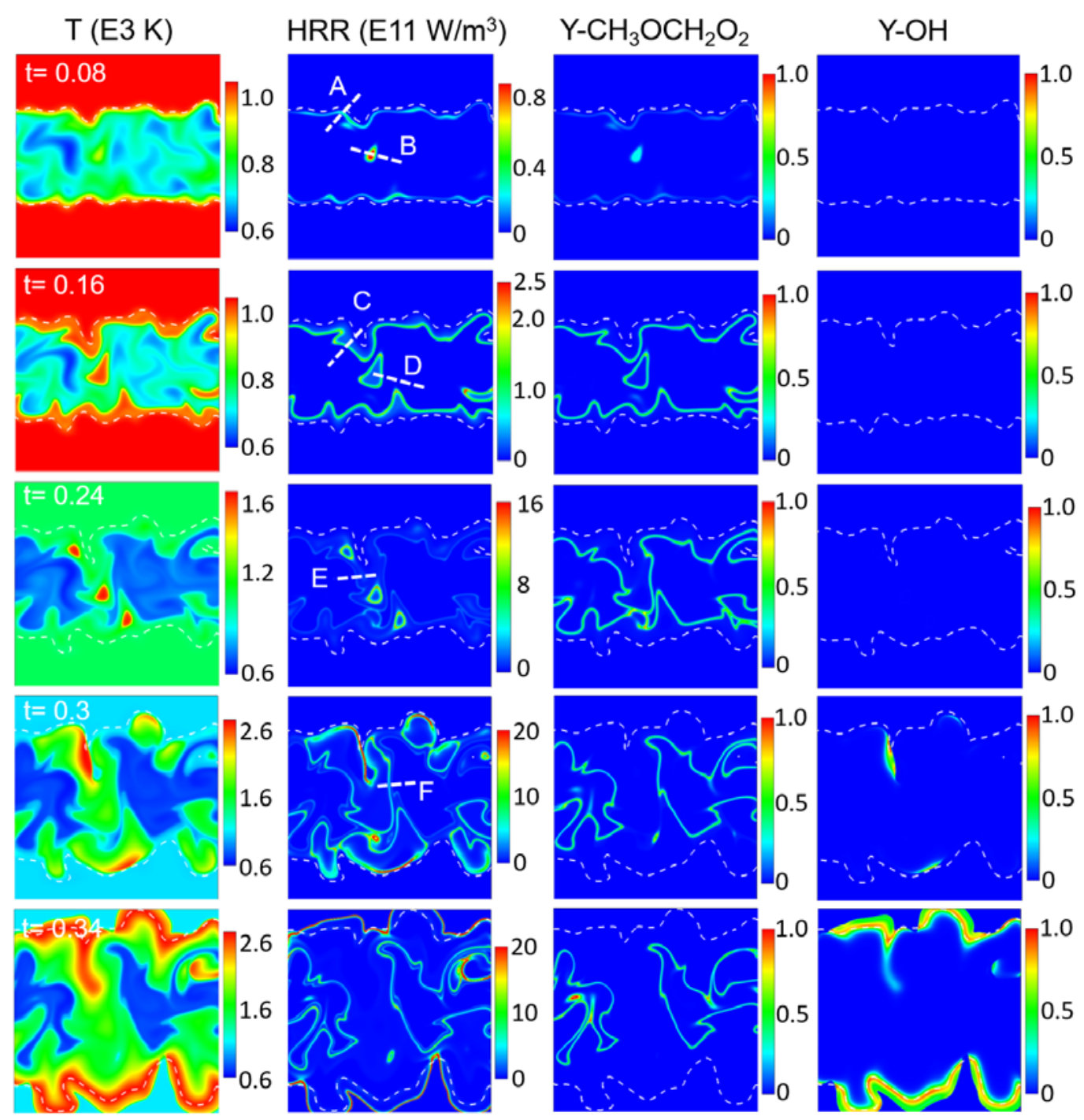

Fig. 8 Iso-contour plots of temperature (T), heat release rate (HRR), normalized mass fraction of $\mathrm{CH}_{3} \mathrm{OCH}_{2} \mathrm{O}_{2}\left(\mathrm{Y}-\mathrm{CH}_{3} \mathrm{OCH}_{2} \mathrm{O}_{2}\right)$ and $\mathrm{OH}(\mathrm{Y}-\mathrm{OH})$ at sequential times $(\mathrm{t}=0.08,0.16,0.24,0.3$, $0.34 \mathrm{~ms}$ ). Each row represents an instant in time. Note the legends are different from each subfigure. The white dashed line corresponds to the stoichiometric iso-line. Lines A-F are marked for later analysis.

\subsection{Conditional statistics}

The evolution of reactive scalars conditioned on $\xi$ can provide more details on the ignition dynamics of a turbulent flow. Statistics gathered over the whole computational domain for selected scalars: T, HRR, mass fraction of $\mathrm{CH}_{3} \mathrm{OCH}_{2} \mathrm{O}_{2}\left(\mathrm{Y}-\mathrm{CH}_{3} \mathrm{OCH}_{2} \mathrm{O}_{2}\right)$, mass fraction of $\mathrm{OH}(\mathrm{Y}-\mathrm{OH})$ are shown in Fig. 9, as well as the conditional means in the mixture fraction space. One third of all points in the computational domain are sampled and shown as scatters. The red solid line in each subfigure represents the mean scalar conditioned on $\xi$ and the error bars 
bracket the mean curve are presented for the conditional standard deviation. At $t=0.08 \mathrm{~ms}$, the low-temperature combustion is dominant with no significant increase of T. The peak HRR is located around $\xi=0.176$. There are scatter points with relatively higher HRR and T, which correspond to points in the central stratified mixture with lower scalar dissipation rate $\chi$. By $\mathrm{t}$ $=0.16 \mathrm{~ms}$, the peak value of HRR moves to the richer mixture, which occupied a broad region in the $\xi$ space. By this time, the distribution of $\mathrm{Y}-\mathrm{CH}_{3} \mathrm{OCH}_{2} \mathrm{O}_{2}$ is quite consistent with the lowtemperature HRR, as well as $\mathrm{Y}-\mathrm{OH}$. However, the value of $\mathrm{Y}-\mathrm{OH}$ is extremely small at this stage. At $t=0.24 \mathrm{~ms}$, extremely high values of HRR can be found at $0.18<\xi<0.25$ with increasing T, which correspond to the high-temperature ignition. The other peak values of HRR, which correspond to LTC continue moving to the richer mixture, while the peak values do not vary a lot. This also indicates LTC would be propagating as a cool flame, which will be discussed in detail in Section 3.3. The magnitude of $\mathrm{Y}-\mathrm{CH}_{3} \mathrm{OCH}_{2} \mathrm{O}_{2}$ decreases at $\xi<0.25$, due to the consumption of $\mathrm{CH}_{3} \mathrm{OCH}_{2} \mathrm{O}_{2}$ by $\mathrm{HTC}$. In this region, $\mathrm{Y}-\mathrm{OH}$ increases significantly, however is still in the order of $10^{-5}$. By $t=0.3 \mathrm{~ms}$, the HRR increases significantly with multiple peaks, which generally correspond to the propagation of edge flames generated from expanding high temperature ignition kernels. The largest value of HRR is located in slightly rich mixture close to $\xi_{\text {st, }}$ which represents the premixed flame branch approaching the $\xi_{\text {st }}$ iso-line. The peak values of HRR in most rich mixture correspond to the propagating cool flame. And the peak HRR in between corresponds to premixed flame branch approaching the cool flame. The value of $\mathrm{Y}-\mathrm{OH}$ increases significantly due to HTC, and its distribution is confined to a narrow band of $\xi$ value, which is well overlapped with HTC. 

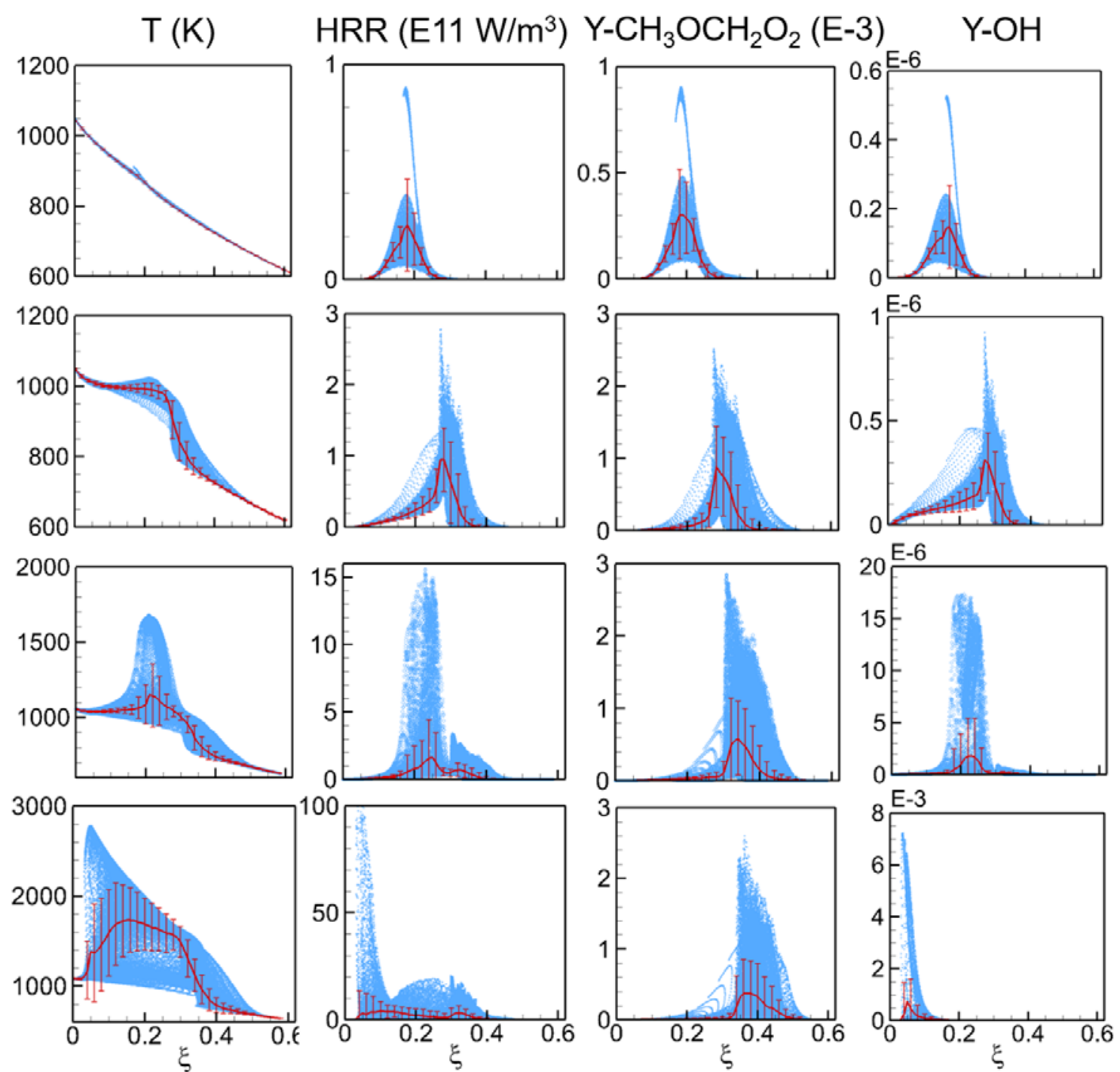

Fig. 9 Conditional statistics of temperature (T), heat release rate (HRR), mass fraction of $\mathrm{CH}_{3} \mathrm{OCH}_{2} \mathrm{O}_{2}\left(\mathrm{Y}-\mathrm{CH}_{3} \mathrm{OCH}_{2} \mathrm{O}_{2}\right)$ and $\mathrm{OH}(\mathrm{Y}-\mathrm{OH})$ at selected instants $(\mathrm{t}=0.08,0.16,0.24,0.3 \mathrm{~ms}$ from top to bottom row) during ignition. Each row represents one instant in time. Scatters represent samples over the domain. The thick red line is the conditional mean, and the error bars correspond to standard deviation.

\subsection{Low-temperature combustion}

Low-temperature heat release has been found to occur via both flame propagation and through ignition fronts in previous RCCI simulations [34]. The analysis is based on the comparisons of reaction and diffusion rates of the $\mathrm{OH}$ radical at the reaction front. It has been recognized as a deflagration flame-based combustion while diffusion and reaction rates are of comparable magnitude, or as an ignition front while the magnitude of the diffusion rate is almost negligible compared with that of the reaction rate. However, in the present case, the 
magnitude of $\mathrm{Y}-\mathrm{OH}$ has been observed to remain extremely small during the low-temperature reaction, which indicates it may be inappropriate to choose $\mathrm{OH}$ radical for the transport analysis. Since $\mathrm{CH}_{3} \mathrm{OCH}_{2} \mathrm{O}_{2}$ is produced only in presence of LTC and consumed by HTC, the role of diffusion in supporting the low-temperature cool flame can be quantified by considering the transport budget analysis for the LTC marker $\mathrm{Y}-\mathrm{CH}_{3} \mathrm{OCH}_{2} \mathrm{O}_{2}$ [38]. Figure 10 shows reaction and diffusion terms of the transport budget of $\mathrm{Y}-\mathrm{CH}_{3} \mathrm{OCH}_{2} \mathrm{O}_{2}$ in addition to $\chi$ evaluated along lines A-F marked in Fig. 8 at different time instants. It can be observed from Fig. 10 (a)\& (b) that autoignition occurs at relatively low $\chi$, where the magnitude of the reaction term is significantly larger than the diffusion term during ignition (line A \& B). It means that the HRR is due to localised first stage of ignition. As time advances, both the reaction and diffusion terms increase, while $\chi$ gradually decreases. Along line $C \& D$ at $\mathrm{t}=0.16 \mathrm{~ms}$, the reaction and diffusion terms have comparable value with opposite sign. This is an evidence of transition from low-temperature autoignition to diffusively-supported propagating cool flame. Finally, at $\mathrm{t}=0.34 \mathrm{~ms}$ after the initiation of the premixed methane-air flame in Fig. 8, the magnitudes of reaction and diffusion terms along line $\mathrm{F}$ are still comparable with opposite signs, confirming the existence of the cool flame in the fuel-rich mixtures.
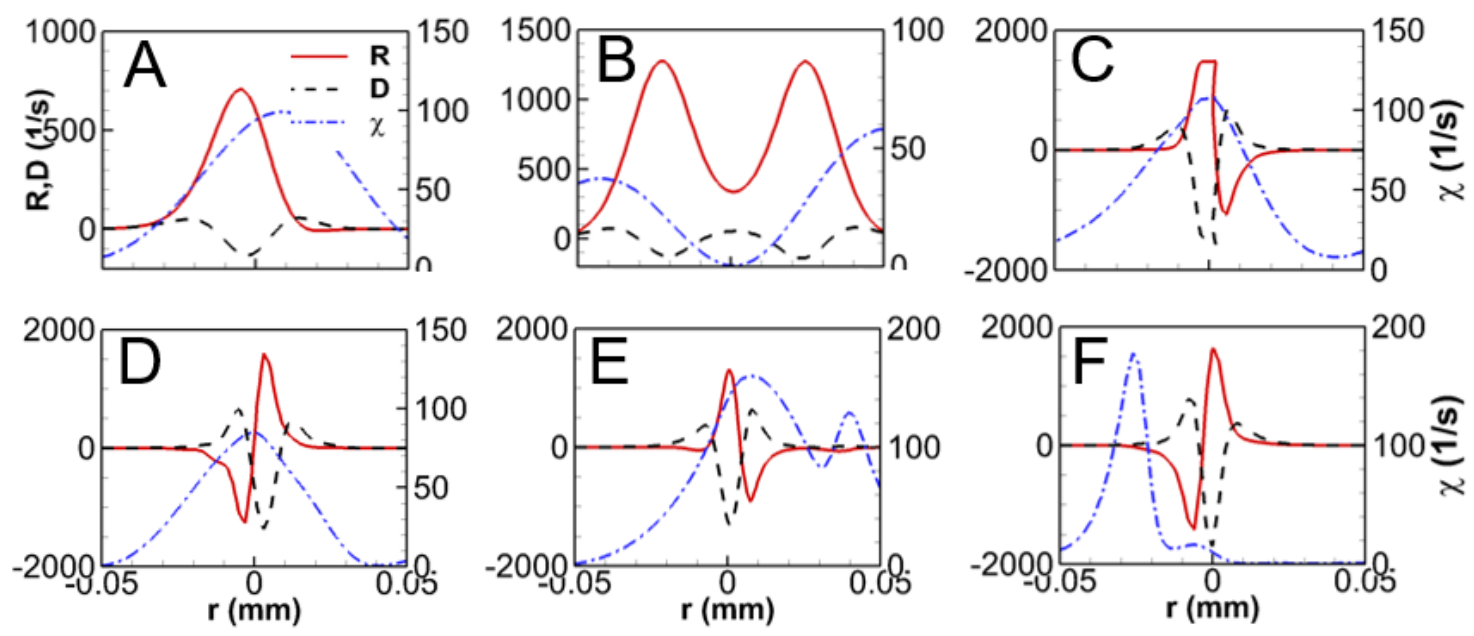

Fig. 10 Transport budget analysis of $\mathrm{Y}-\mathrm{CH}_{3} \mathrm{OCH}_{2} \mathrm{O}_{2}$, along lines A-F marked in Fig. 8. The reaction $(\mathrm{R})$ and diffusion $(\mathrm{D})$ terms on the left $y$-axes, and scalar dissipation rate $\chi$ on the right $\mathrm{y}$-axes. $\mathrm{r}$ is the distance from low temperature reaction zone. 
Through the transition from low-temperature autoignition to cool flame and followed, the cool flame has been observed to move up to the fuel richer mixture. In order to identify the location of the cool flame in the mixture fraction $\xi$ space, a volume may be defined that bounds the HRR due to LTC. The species $\mathrm{CH}_{3} \mathrm{OCH}_{2} \mathrm{O}_{2}$ is a good marker for LTC as shown in Fig. 8, as it is seriously consistent with the low-temperature heat release. It is also consumed at high temperatures and can isolate regions of LTC from HTC. Thus, it is appropriate to be adopted for defining the locations of the cool flame. In the present case, the cool flame is defined to exist where $\mathrm{Y}-\mathrm{CH}_{3} \mathrm{OCH}_{2} \mathrm{O}_{2}>2.0 \mathrm{e}-4$, which is $10 \%$ of the maximum value observed during the simulation. The evolution of the probability density function (PDF) of $\xi$ conditioned upon the LTC locations is described in Fig. 11. The PDF initiates as a narrow profile at leaner $\xi$. As time advances, the PDF gradually moves into richer $\xi$ and becomes increasingly broad up. The $\xi_{\mathrm{p}}$ corresponding to the peak PDF, significantly increases from $t=0.08 \mathrm{~ms}$ to $\mathrm{t}=0.12 \mathrm{~ms}$. This is relevant to the transition from ignition to cool flame. Thereafter, the $\xi_{\mathrm{p}}$ increases at a generally constant rate, but a smaller rate from $\mathrm{t}=0.24 \mathrm{~ms}$ to $\mathrm{t}=0.32 \mathrm{~ms}$ to the very rich mixture by the end of the simulation.

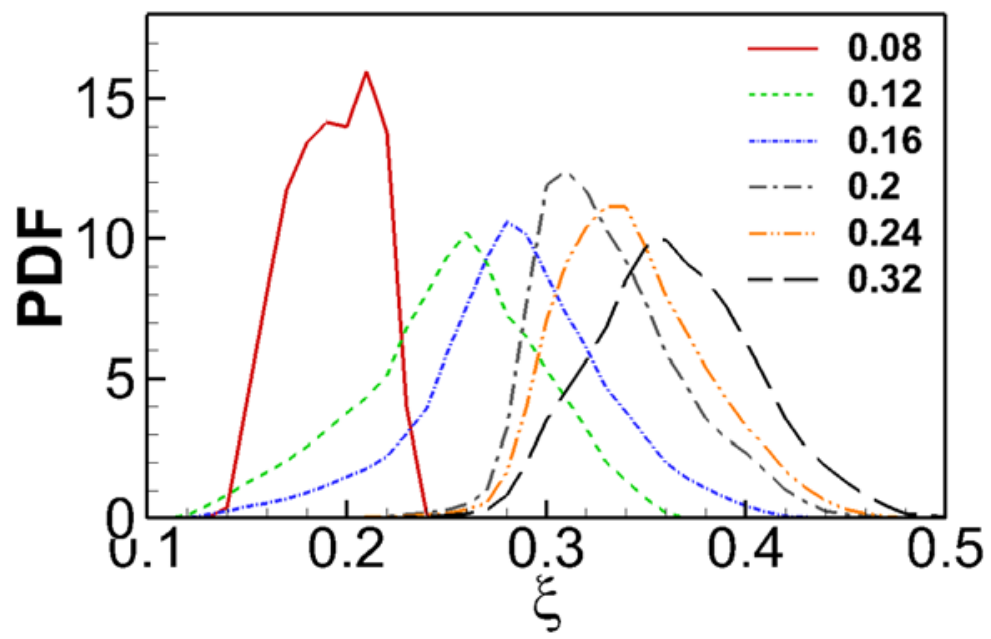

Fig. 11 PDF of $\xi$ conditioned upon the cool-flame locations.

\subsection{High-temperature ignition and flame development}

High-temperature ignition kernels prefer to occur at distributed locations. The exact locations of kernel formation are important for the overall ignition and stabilization process, 
and also important for the conceptual models of diesel-methane dual fuel combustion. In this section, statistics are extracted from the high-temperature ignition kernels. As proposed by Krisman et al. [38], an ignition kernel is defined as a local maximum of HRR which emerges from a point-source due to autoignition. The kernel formation is defined as the instant at which the peak in HRR exceeds 4E11 W/m³. Accordingly, 29 kernels are found. In Fig. 12 (a), the time instants at which high temperature autoignition kernels occur, are compared with the firststage $(\tau 1)$ and second-stage $(\tau)$ ignition delay time measured in the homogeneous reactor. Autoignition kernels form in fuel-rich mixtures with a wide range of mixture fraction around $\xi_{\mathrm{mr}}$ and richer mixture. The formation times of the high temperature ignition kernels (HIKs) vary up to $30 \%$ longer than $\tau_{\left(\xi=\xi_{m r}\right)}$. The occurrence of the first HIK is at $\mathrm{t}=0.985 \tau_{\left(\xi=\xi_{m r}\right)}$ with the mixture fraction of 0.2237 , which is richer than $\xi_{\mathrm{mr}, 2}=0.195$.

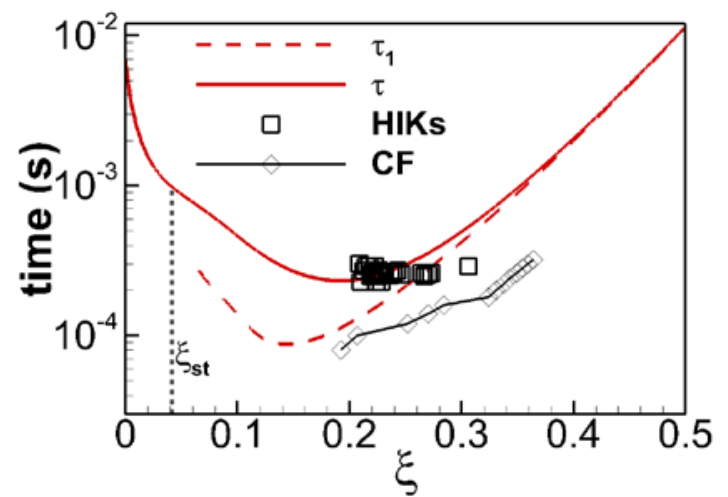

(a)

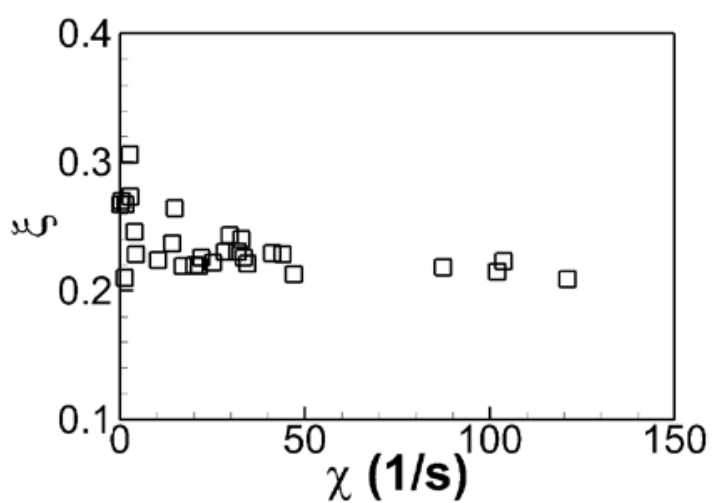

(b)

Fig. 12 (a) Comparison of high-temperature ignition and cool-flame times with homogeneous ignition delay time $\tau 1$ and $\tau$. (b) Scatters of scalar dissipation rate $\chi$ and mixture fraction $\xi$ at HIKs.

Several autoignition kernels occur in very rich mixtures much earlier than in the homogeneous mixture at the corresponding mixture fraction, which is thought to be accelerated by the cool flame. The evolution of the mean $\xi$ evaluated at the locations of cool flame is also shown in Fig. 12. The corresponding time is observed significantly smaller than the first-stage ignition time $(\tau 1)$, which also indicates the cool flame accelerates the LTC.

The ignition and flame developing processes are seriously affected by the turbulent flow field. Turbulent mixing induces a wide range of scalar dissipation rate $\chi\left(\chi=2 D\left(\partial \xi / \partial x_{i}\right)^{2}\right)$, 
which has been proven to significantly influence autoignition [59]. High $\chi$ values result in low heat release rate and even the absence of ignition. Figure 12(b) shows the values of $\chi$ at the high-temperature ignition kernels, which is quite small regarding the maximum value of $\chi$ in the computational domain is $1100 \mathrm{~s}^{-1}$.

Sequential development of two typical high-temperature kernels is shown in Fig. 13. Although heat release rate increases faster to be high enough forming the ignition kernels, HRR in the neighboring region is also relatively high. The expanding flames prefer to propagate faster into the autoigniting mixture, other than to the lean mixture. In other words, the speed of the flame propagating into the partially autoigniting mixture would be faster. The expanding flames have been connected with the neighboring flames before they engulf the $\xi_{\text {st }}$ iso-line, thus explicit propagating of triple flame along the $\xi_{\text {st }}$ iso-line cannot be observed. This is different from the results obtained in our previous study [41], where the expanding flames quickly engulf the $\xi_{\text {st }}$ iso-line and form triple flames. The triple flames propagate toward and finally connect with each other. One of the reasons is the values of $\chi$ at that case is relatively high, which inhibits the autoigniting of the mixtures in fuel-rich mixtures. Nevertheless, the four branches of typical tetrabranchial flames (i.e. cool flame, fuel-rich premixed flame, diffusion flame, fuel lean premixed flame) [53] are coexisting in the field in the present case. 

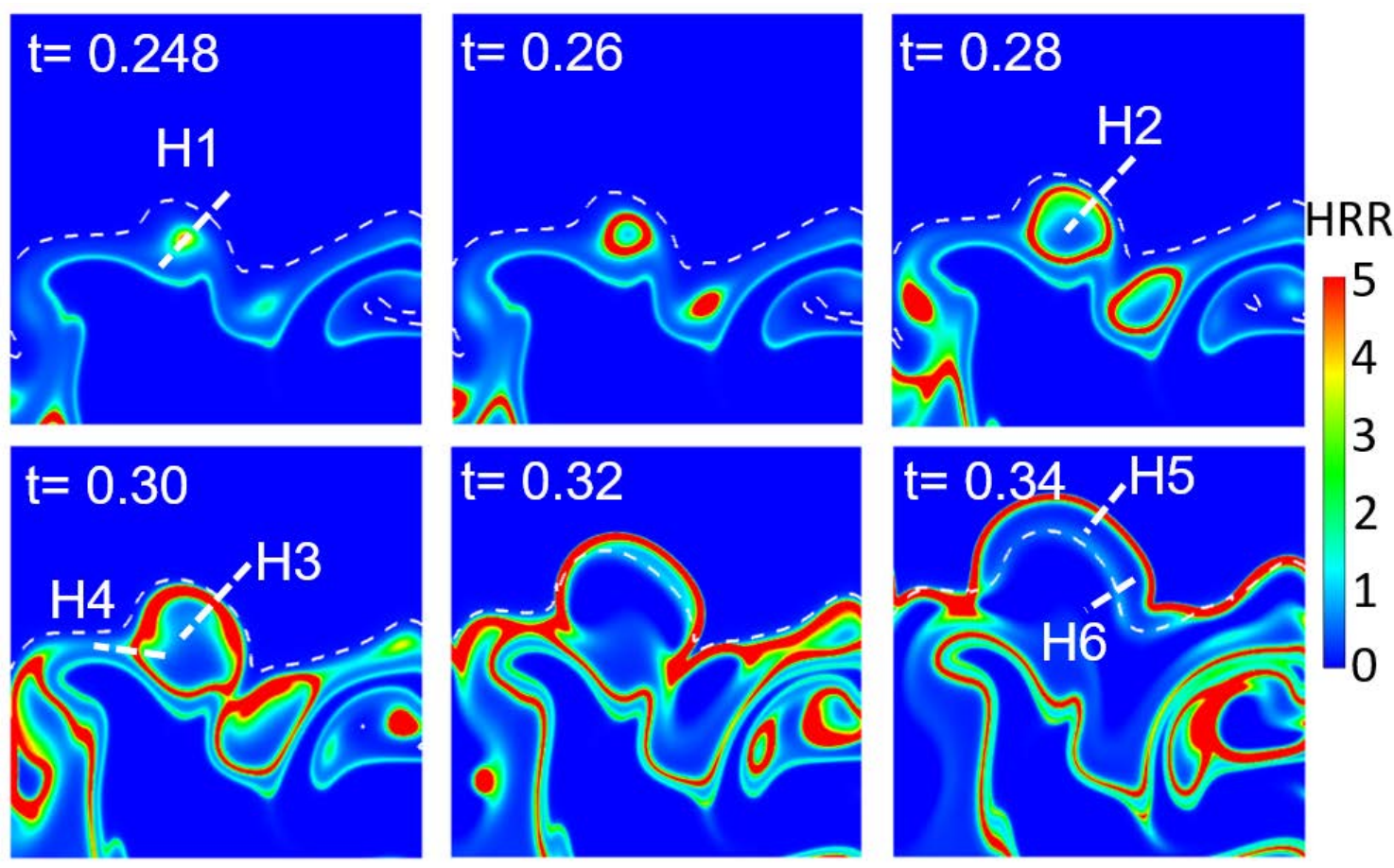

Fig. 13 Temporal evolution of heat release rate $\left(H R R E 11 \mathrm{~W} / \mathrm{m}^{3}\right)$ for a fixed window of the domain at time instants $(\mathrm{t}=0.248-0.34 \mathrm{~ms})$. The white dashed line is the stoichiometric mixture iso-line. Lines H1-6 are marked for later analysis.

The transport budget analysis for the key HTC intermediate the hydroxyl $(\mathrm{OH})$ along the selected lines H1-6 is conducted to distinguish the high-temperature autoignition from flames. The reaction (R) and diffusion (D) terms are compared in Fig. 14, as well as the scalar dissipation rate $(\chi)$. Line $\mathrm{H} 1$ is extracted from an ignition kernel, with the reaction term is significantly larger than the diffusion term. The scalar dissipation rate $\chi$ corresponds to the ignition kernel is relatively low. Line H2 is extracted across the branch of the expanding kernel approaching the fuel lean mixture. The ignition kernel transits to a propagating flame, as the magnitudes of the reaction and diffusion (D) terms become comparable with opposite sign. The local value of $\chi$ is observed to increase due to flame compared with that along H1. While this flame branch propagates close to the $\xi_{\text {st }}$ iso-line, the magnitudes of the reaction and diffusion terms significantly increase to an extremely high level, which indicates a much faster reaction. This branch further triggers the premixed methane-air flame with even higher reaction and diffusion along the flame front H5. It can also be found that the thickness of the flame front gradually decreases from $\mathrm{H} 2$ to $\mathrm{H} 3$ and till $\mathrm{H} 5$. Line $\mathrm{H} 4$ is extracted along the propagation of 
the expanding kernel to the neighboring partially reacted mixture. The magnitudes of $\mathrm{R}$ and $\mathrm{D}$ is found to be larger than that along H2, which helps the faster propagation of the kernel to the neighboring mixture. Line $\mathrm{H} 6$ is extracted across the diffusion flame along the $\xi_{\text {st }}$ iso-line. The diffusion flame has high rates of formation of $\mathrm{Y}-\mathrm{OH}$ and a balanced reaction-diffusion, and occupies a much broader region of space compared to the premixed branches. Overall, the transport budget analysis of $\mathrm{Y}-\mathrm{OH}$ confirms that the high-temperature ignition kernels rapidly transit to expanding premixed flames. The branch approaching the fuel lean mixture engulfs the $\xi_{\text {st }}$ surface and finally initiates the premixed methane-air flame. The typical four branches of tetrabranchial flames are not simply autoignition fronts but involve significant amounts of molecular diffusion.
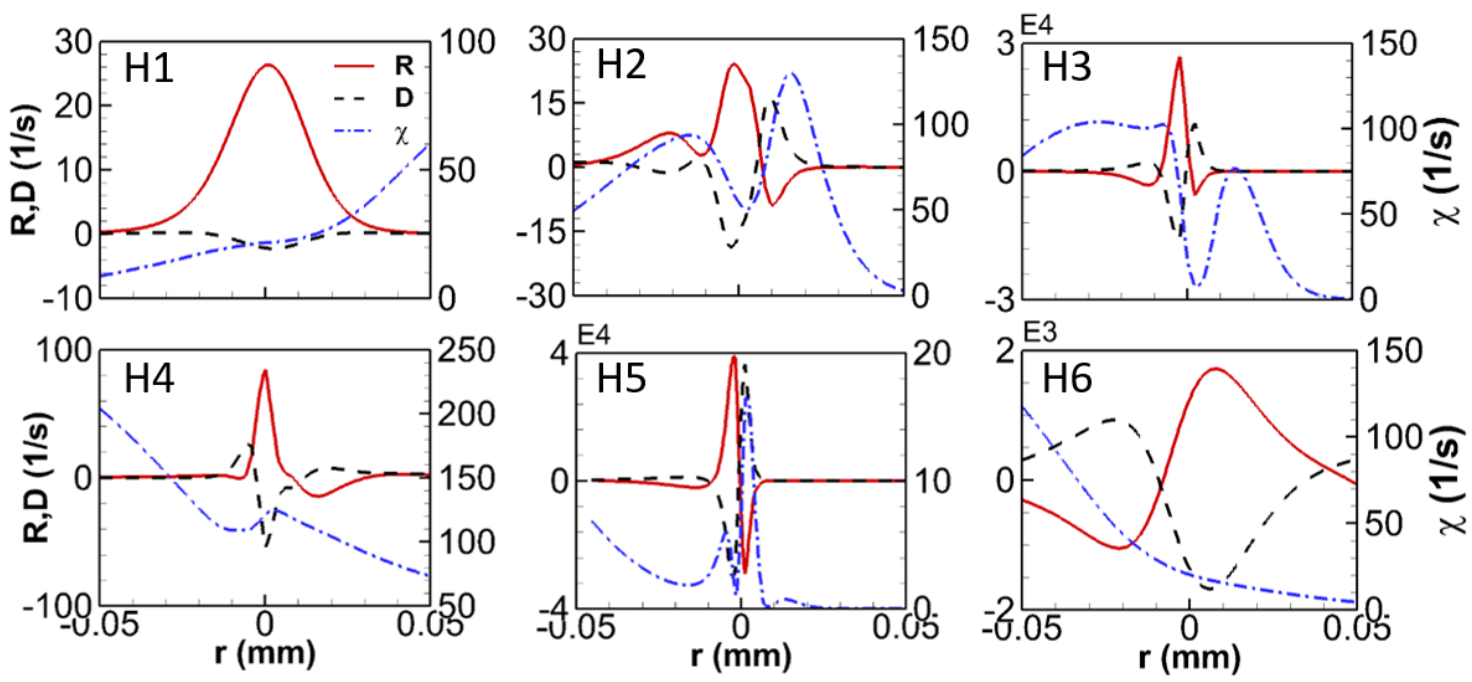

Fig. 14 Transport budget analysis of Y-OH, along lines H1-6 marked in Fig. 13. The reaction (R) and diffusion (D) terms on the left y-axes, and scalar dissipation rate $\chi$ on the right y-axes. $r$ is the distance from high-temperature reaction front.

\section{Conclusions}

In the present paper, ignition dynamics in DME/methane-air mixture under RCCI conditions was investigated using DNS. The initial conditions are set to mimic the situation right after injection of DME, where the directly-injected DME and in-cylinder premixed methane-air mixture are partially mixed and form a mixing layer in between. The initial 
stratified composition profile is perturbed by a decaying random velocity field. The adopted chemical mechanism, consisting of 25 species in 147 reaction steps, is reduced from a detailed DME/CH4 $\mathrm{CH}_{4}$ oxidization mechanism (Mech_56.54). The transient ignition and flame development process is first demonstrated. It is found that ignition occurs as a two-stage process while low-temperature combustion strongly influences high-temperature ignition. Low-temperature autoignition is first initiated in fuel rich mixture and moves up against the mixture fraction gradient. Transport budget analysis for the LTC marker $\mathrm{Y}-\mathrm{CH}_{3} \mathrm{OCH}_{2} \mathrm{O}_{2}$ provides the evidence for transition from low-temperature autoignition to diffusion-supported cool flame. Cool flames not only develop in the mixing layer, but also in the initially stratified DME/methane-air mixture in the central region.

High-temperature ignition kernels prefer to occur at distributed locations with low scalar dissipation rate. Several autoignition kernels occurring in very rich mixtures form much earlier than in the homogeneous mixture at the same mixture fraction, which is thought to be accelerated by the cool flame. The four branches of typical tetrabranchial flames, i.e., cool flame, fuel-rich premixed flame, diffusion flame, fuel-lean premixed flame still coexist in the field. The fuel-lean premixed flame branch finally triggers the premixed methane-air flame. Transport budget analysis of Y-OH (the HTC marker) confirms the rapid transition from hightemperature ignition to diffusion-supported flames.

The transitions from low-temperature autoignition to cool flames have been observed in previous studies of mixing layers between DME/air [37, 38, 53], DME/methane-air [41], as well as jets of heptane and n-dodecane in air [39, 40]. However, such a phenomenon has not been explicitly observed and presented in previous simulations of RCCI combustion in a stratified mixture [33-35]. Further work is needed to understand how the cool flame can be affected by key parameters such as composition and temperature stratification, mixing layer thickness, shear-layer turbulence, as well as its precise modeling. 


\section{Nomenclature}

Da Damköhler number

$l$ length scale (m)

$L$ domain length scale (m)

$T$ temperature (K)

$t$ time (s)

$u$ velocity $(\mathrm{m} / \mathrm{s})$

$Y_{\mathrm{k}}$ mass fraction of species $k$

$\xi$ mixture fraction

$\chi$ scalar dissipation rate (1/s)

$\tau$ ignition delay time (s)

$\delta$ thickness of mixing layer (m)

Subscript

mr most reactive mixture

turb turbulent

st stoichiometric

Abbreviation

CFD computational fluid dynamics

CI compression ignition 
CO carbon monoxide

DF dual fuel

DME dimethyl ether

DNS direct numerical simulation

HC hydrocarbon

HTC high-temperature combustion

HRR heat release rate

HIK high-temperature ignition kernel

LTC low-temperature combustion

LES large-eddy simulation

NG natural gas

PDF probability density function

PRF primary reference fuel

RPF rich premixed flame

RANS Reynolds’ Averaged Navier-stokes

RCCI Reactivity-Controlled Compression Ignition

SCCI stratified charge compression ignition

TDC top dead center 


\section{Acknowledgements}

This work is supported by the National Natural Science Foundation of China (No. 51576176). Supercomputing time on ARCHER provided under the UK Engineering and Physical Sciences Research Council (EPSRC) projects "UK Consortium on Mesoscale Engineering Sciences (UKCOMES)" (Grants No. EP/L00030X/1 and No. EP/R029598/1) and "High Performance Computing Support for United Kingdom Consortium on Turbulent Reacting Flow (UKCTRF)” (Grant No. EP/K024876/1) is gratefully acknowledged. Tai Jin acknowledges the financial support under the International Postdoctoral Exchange Fellowship Program during his visit at University College London, UK.

\section{Reference}

[1] Tuner M. Review and Benchmarking of Alternative Fuels in Conventional and Advanced Engine Concepts with Emphasis on Efficiency, CO2, and Regulated Emissions. SAE International; 2016.

[2] Belgiorno G, Di Blasio G, Beatrice C. Parametric study and optimization of the main engine calibration parameters and compression ratio of a methane-diesel dual fuel engine. Fuel. 2018;222:821-40.

[3] Belgiorno G, Di Blasio G, Shamun S, Beatrice C, Tunestål P, Tunér M. Performance and emissions of diesel-gasoline-ethanol blends in a light duty compression ignition engine. Fuel. 2018;217:78-90.

[4] Wei L, Geng P. A review on natural gas/diesel dual fuel combustion, emissions and performance. Fuel Processing Technology. 2016;142:264-78.

[5] Mikulski M, Bekdemir C. Understanding the role of low reactivity fuel stratification in a dual fuel RCCI engine - A simulation study. Applied Energy. 2017;191:689-708. 
[6] Vávra J, Bortel I, Takáts M, Diviš M. Emissions and performance of diesel-natural gas dual-fuel engine operated with stoichiometric mixture. Fuel. 2017;208:722-33.

[7] Dahodwala M, Joshi S, Koehler E, Franke M, Tomazic D. Experimental and Computational Analysis of Diesel-Natural Gas RCCI Combustion in Heavy-Duty Engines. SAE International; 2015.

[8] Namasivayam AM, Korakianitis T, Crookes RJ, Bob-Manuel KDH, Olsen J. Biodiesel, emulsified biodiesel and dimethyl ether as pilot fuels for natural gas fuelled engines. Applied Energy. 2010;87:769-78.

[9] Rahnama P, Paykani A, Reitz RD. A numerical study of the effects of using hydrogen, reformer gas and nitrogen on combustion, emissions and load limits of a heavy duty natural gas/diesel RCCI engine. Applied Energy. 2017;193:182-98.

[10] Daniel R, Xu H, Wang C, Richardson D, Shuai S. Combustion performance of 2,5dimethylfuran blends using dual-injection compared to direct-injection in a SI engine. Applied Energy. 2012;98:59-68.

[11] Kokjohn SL, Hanson RM, Splitter DA, Reitz RD. Experiments and Modeling of DualFuel HCCI and PCCI Combustion Using In-Cylinder Fuel Blending. SAE Int J Engines. 2009;2:24-39.

[12] Benajes J, Pastor JV, García A, Monsalve-Serrano J. The potential of RCCI concept to meet EURO VI NOx limitation and ultra-low soot emissions in a heavy-duty engine over the whole engine map. Fuel. 2015;159:952-61.

[13] Reitz RD, Duraisamy G. Review of high efficiency and clean reactivity controlled compression ignition (RCCI) combustion in internal combustion engines. Progress in Energy and Combustion Science. 2015;46:12-71. 
[14] Paykani A, Kakaee A-H, Rahnama P, Reitz RD. Progress and recent trends in reactivitycontrolled compression ignition engines. International Journal of Engine Research. 2015;17:481-524.

[15] Li J, Yang W, Zhou D. Review on the management of RCCI engines. Renewable and Sustainable Energy Reviews. 2017;69:65-79.

[16] Ansari E, Poorghasemi K, Khoshbakht Irdmousa B, Shahbakhti M, Naber J. Efficiency and Emissions Mapping of a Light Duty Diesel - Natural Gas Engine Operating in Conventional Diesel and RCCI Modes. SAE International; 2016.

[17] Kakaee A-H, Rahnama P, Paykani A. Influence of fuel composition on combustion and emissions characteristics of natural gas/diesel RCCI engine. Journal of Natural Gas Science and Engineering. 2015;25:58-65.

[18] Benajes J, Molina S, García A, Monsalve-Serrano J. Effects of direct injection timing and blending ratio on RCCI combustion with different low reactivity fuels. Energy Conversion and Management. 2015;99:193-209.

[19] Benajes J, Molina S, García A, Monsalve-Serrano J. Effects of low reactivity fuel characteristics and blending ratio on low load RCCI (reactivity controlled compression ignition) performance and emissions in a heavy-duty diesel engine. Energy. 2015;90:1261-71.

[20] Dempsey AB, Walker NR, Reitz R. Effect of Cetane Improvers on Gasoline, Ethanol, and Methanol Reactivity and the Implications for RCCI Combustion. SAE International Journal of Fuels and Lubricants. 2013;6:170-87.

[21] Dempsey AB, Curran S, Reitz RD. Characterization of Reactivity Controlled Compression Ignition (RCCI) Using Premixed Gasoline and Direct-Injected Gasoline with a Cetane Improver on a Multi-Cylinder Engine. SAE International Journal of Engines. 2015;8:859-77. 
[22] Ansari E, Menucci T, Shahbakhti M, Naber J. Experimental investigation into effects of high reactive fuel on combustion and emission characteristics of the Diesel - Natural gas Reactivity Controlled Compression Ignition engine. Applied Energy. 2019;239:948-56.

[23] Desantes JM, Benajes J, García A, Monsalve-Serrano J. The role of the in-cylinder gas temperature and oxygen concentration over low load reactivity controlled compression ignition combustion efficiency. Energy. 2014;78:854-68.

[24] Kokjohn S, Reitz RD, Splitter D, Musculus M. Investigation of Fuel Reactivity Stratification for Controlling PCI Heat-Release Rates Using High-Speed Chemiluminescence Imaging and Fuel Tracer Fluorescence. SAE Int J Engines. 2012;5:248-69.

[25] Kokjohn SL, Musculus MPB, Reitz RD. Evaluating temperature and fuel stratification for heat-release rate control in a reactivity-controlled compression-ignition engine using optical diagnostics and chemical kinetics modeling. Combustion and Flame. 2015;162:2729-42.

[26] Tang Q, Liu H, Li M, Geng C, Yao M. Multiple optical diagnostics on effect of fuel stratification degree on reactivity controlled compression ignition. Fuel. 2017;202:688-98.

[27] Srna A, Bolla M, Wright YM, Herrmann K, Bombach R, Pandurangi SS, et al. Effect of methane on pilot-fuel auto-ignition in dual-fuel engines. Proceedings of the Combustion Institute. 2019;37:4741-9.

[28] Nieman DE, Dempsey AB, Reitz RD. Heavy-Duty RCCI Operation Using Natural Gas and Diesel. SAE International Journal of Engines: SAE International; 2012. p. 270-85.

[29] Poorghasemi K, Saray RK, Ansari E, Irdmousa BK, Shahbakhti M, Naber JD. Effect of diesel injection strategies on natural gas/diesel RCCI combustion characteristics in a light duty diesel engine. Applied Energy. 2017;199:430-46.

[30] Li J, Ling X, Liu D, Yang W, Zhou D. Numerical study on double injection techniques in a gasoline and biodiesel fueled RCCI (reactivity controlled compression ignition) engine. Applied Energy. 2018;211:382-92. 
[31] Benajes J, Molina S, García A, Belarte E, Vanvolsem M. An investigation on RCCI combustion in a heavy duty diesel engine using in-cylinder blending of diesel and gasoline fuels. Applied Thermal Engineering. 2014;63:66-76.

[32] Zhou D, Yang W, Zhao F, Li J. Dual-fuel RCCI engine combustion modeling with detailed chemistry considering flame propagation in partially premixed combustion. Applied Energy. 2017;203:164-76.

[33] Luong MB, Yu GH, Chung SH, Yoo CS. Ignition of a lean PRF/air mixture under RCCI/SCCI conditions: A comparative DNS study. Proceedings of the Combustion Institute. 2017;36:3623-31.

[34] Bhagatwala A, Sankaran R, Kokjohn S, Chen JH. Numerical investigation of spontaneous flame propagation under RCCI conditions. Combustion and Flame. 2015;162:3412-26.

[35] Luong MB, Yu GH, Chung SH, Yoo CS. Ignition of a lean PRF/air mixture under RCCI/SCCI conditions: Chemical aspects. Proceedings of the Combustion Institute. 2017;36:3587-96.

[36] Pickett LM, Kook S, Williams TC. Visualization of Diesel Spray Penetration, Cool-Flame, Ignition, High-Temperature Combustion, and Soot Formation Using High-Speed Imaging. SAE Int J Engines. 2009;2:439-59.

[37] Krisman A, Hawkes ER, Talei M, Bhagatwala A, Chen JH. Characterisation of two-stage ignition in diesel engine-relevant thermochemical conditions using direct numerical simulation. Combustion and Flame. 2016;172:326-41.

[38] Krisman A, Hawkes ER, Talei M, Bhagatwala A, Chen JH. A direct numerical simulation of cool-flame affected autoignition in diesel engine-relevant conditions. Proceedings of the Combustion Institute. 2017;36:3567-75.

[39] Krisman A, Hawkes ER, Chen JH. Two-stage autoignition and edge flames in a high pressure turbulent jet. J Fluid Mech. 2017;824:5-41. 
[40] Borghesi G, Krisman A, Lu TF, Chen JH. Direct numerical simulation of a temporally evolving air/n-dodecane jet at low-temperature diesel-relevant conditions. Combustion and Flame. 2018;195:183-202.

[41] Jin T, Luo KH, Wang X, Luo K, Fan J. Dynamics of triple-flames in ignition of turbulent dual fuel mixture: A direct numerical simulation study. Proceedings of the Combustion Institute. 2019;37:4625-33.

[42] Yu GH, Luong MB, Chung SH, Yoo CS. A DNS Study of Ignition Characteristics of a Lean PRF/Air Mixture with Mixing Layer under RCCIConditions. 55th KOSCO Symposium. Yeosu, Korea2017.

[43] Arcoumanis C, Bae C, Crookes R, Kinoshita E. The potential of di-methyl ether (DME) as an alternative fuel for compression-ignition engines: A review. Fuel. 2008;87:1014-30.

[44] Ano TA, Dryer FL. Effect of dimethyl ether, NOx, and ethane on CH4 oxidation: High pressure, intermediate-temperature experiments and modeling. Symposium (International) on Combustion. 1998;27:397-404.

[45] Chen Z, Qin X, Ju Y, Zhao Z, Chaos M, Dryer FL. High temperature ignition and combustion enhancement by dimethyl ether addition to methane-air mixtures. Proceedings of the Combustion Institute. 2007;31:1215-22.

[46] Liu J, Yang F, Wang H, Ouyang M. Numerical study of hydrogen addition to DME/CH4 dual fuel RCCI engine. International Journal of Hydrogen Energy. 2012;37:8688-97.

[47] Chen Z, Yao M, Zheng Z, Zhang Q. Experimental and Numerical Study of Methanol/Dimethyl Ether Dual-Fuel Compound Combustion. Energy \& Fuels. 2009;23:271930.

[48] Yu R, Bai X-S. Direct numerical simulation of lean hydrogen/air auto-ignition in a constant volume enclosure. Combustion and Flame. 2013;160:1706-16. 
[49] Bansal G, Mascarenhas A, Chen JH. Direct numerical simulations of autoignition in stratified dimethyl-ether (DME)/air turbulent mixtures. Combustion and Flame. 2015;162:688702.

[50] Robert J. Kee FMR, Ellen Meeks, James A. Miller. CHEMKIN-III: A Fortran Chemical Kinetics Package for the Analysis of Gas Phase Chemical and Plasma Kinetics. Sandia National Laboratories Report 1996.

[51] Luo K, Wang H, Yi F, Fan J. Direct Numerical Simulation Study of an Experimental Lifted H2/N2 Flame. Part 1: Validation and Flame Structure. Energy \& Fuels. 2012;26:611827.

[52] Jin T, Luo K, Lu S, Fan J. DNS investigation on flame structure and scalar dissipation of a supersonic lifted hydrogen jet flame in heated coflow. International Journal of Hydrogen Energy. 2013;38:9886-96.

[53] Jin T, Wang X, Luo KH, Luo K, Fan J. Structure of tetrabrachial flames in non-premixed autoigniting dimethyl ether/air mixtures. Fuel. 2018;232:90-8.

[54] Burke U, Somers KP, O’Toole P, Zinner CM, Marquet N, Bourque G, et al. An ignition delay and kinetic modeling study of methane, dimethyl ether, and their mixtures at high pressures. Combustion and Flame. 2015;162:315-30.

[55] Zheng XL, Lu TF, Law CK. Experimental counterflow ignition temperatures and reaction mechanisms of 1,3-butadiene. Proceedings of the Combustion Institute. 2007;31:367-75.

[56] Lu, Law CK. Systematic Approach To Obtain Analytic Solutions of Quasi Steady State Species in Reduced Mechanisms. The Journal of Physical Chemistry A. 2006;110:13202-8. [57] $\mathrm{Lu} \mathrm{T}$, Law CK. A criterion based on computational singular perturbation for the identification of quasi steady state species: A reduced mechanism for methane oxidation with NO chemistry. Combustion and Flame. 2008;154:761-74. 
[58] Lu T, Law CK, Yoo CS, Chen JH. Dynamic stiffness removal for direct numerical simulations. Combustion and Flame. 2009;156:1542-51.

[59] Mastorakos E. Ignition of turbulent non-premixed flames. Progress in Energy and Combustion Science. 2009;35:57-97. 


\section{List of figure captions}

Fig. 1 Sketch of the computational domain

Fig.2 Initial conditions of temperature, mixture fraction, mass fraction of DME and $\mathrm{CH}_{4}$

Fig. 3. Ignition delay times for stoichiometric $\mathrm{DME} / \mathrm{CH}_{4} /$ air mixtures with different $\mathrm{DME}$ mole percentages at $40 \mathrm{~atm}$ based on the detailed (black line) and reduced mechanisms (red symbols).

Fig. 4. Extinction residence times and extinction temperatures of PSR for stoichiometric $\mathrm{DME} / \mathrm{CH}_{4} / \mathrm{air}$ mixtures with different DME mole percentages at $40 \mathrm{~atm}$ based on the detailed (black line) and reduced mechanism (red symbols).

Fig. 5. Laminar flame speeds for $\mathrm{DME} / \mathrm{CH}_{4} /$ air mixtures as a function of equivalence ratio at $40 \mathrm{~atm}$ and a free stream temperature of $300 \mathrm{~K}$ based on the detailed (black line) and reduced mechanism (red symbols).

Fig. 6 (a) Homogeneous ignition delay time in the mixture fraction space and the scatter distribution of the DNS case, spatially distribution of (b) the first-stage ignition delay time and (c) the second-stage ignition delay time at the initial condition.

Fig. 7 Profiles of temperature (T) and heat release rate (HRR) with different grid sizes,(a) at t $=0.1 \mathrm{~ms}$; (b) at $\mathrm{t}=0.1 \mathrm{~ms}$.

Fig. 8 Iso-contours plots of temperature (T), heat release rate (HRR), normalized mass fraction of $\mathrm{CH}_{3} \mathrm{OCH}_{2} \mathrm{O}_{2}\left(\mathrm{Y}-\mathrm{CH}_{3} \mathrm{OCH}_{2} \mathrm{O}_{2}\right)$ and $\mathrm{OH}(\mathrm{Y}-\mathrm{OH})$ at sequential times $(\mathrm{t}=0.08,0.16,0.24,0.3$, $0.34 \mathrm{~ms})$. Each row represents an instant in time. Note the legends are different from each subfigure. The white dashed line corresponds to the stoichiometric iso-line. Lines A-F are marked for later analysis.

Fig. 9 Conditional statistics of temperature (T), heat release rate (HRR), mass fraction of $\mathrm{CH}_{3} \mathrm{OCH}_{2} \mathrm{O}_{2}\left(\mathrm{Y}-\mathrm{CH}_{3} \mathrm{OCH}_{2} \mathrm{O}_{2}\right)$ and $\mathrm{OH}(\mathrm{Y}-\mathrm{OH})$ at selected instants $(\mathrm{t}=0.08,0.16,0.24,0.3 \mathrm{~ms}$ from top to bottom row) during ignition. Each row represents one instant in time. Scatters represent samples over the domain. The thick red line is the conditional mean, and the error bars correspond to standard deviation. 
Fig. 10 Transport budget analysis of $\mathrm{Y}-\mathrm{CH}_{3} \mathrm{OCH}_{2} \mathrm{O}_{2}$, along lines A-F marked in Fig. 8. The reaction (R) and diffusion (D) terms on the left y-axes, and scalar dissipation rate $\chi$ on the right $\mathrm{y}$-axes. $\mathrm{r}$ is the distance from low temperature reaction zone.

Fig. 11 PDF of $\xi$ conditioned upon the cool-flame locations.

Fig. 12 (a) Comparison of high-temperature ignition and cool-flame times with homogeneous ignition delay time $\tau 1$ and $\tau$. (b) Scatters of scalar dissipation rate $\chi$ and mixture fraction $\xi$ at HIKs.

Fig. 123 Temporal evolution of heat release rate $\left(\mathrm{HRR} \mathrm{E} 11 \mathrm{~W} / \mathrm{m}^{3}\right)$ for a fixed window of the domain at time instants $(\mathrm{t}=0.248-0.34 \mathrm{~ms})$. The white dashed line is the stoichiometric mixture iso-line. Lines H1-6 are marked for later analysis.

Fig. 14 Transport budget analysis of Y-OH, along lines H1-6 marked in Fig. 13. The reaction (R) and diffusion (D) terms on the left y-axes, and scalar dissipation rate $\chi$ on the right $y$-axes. $r$ is the distance from high temperature reaction front. 